\title{
La construcción del Alcázar de Sevilla. Replanteo, cimentaciones y murallas fundacionales ${ }^{(*)}$
}

\section{The construction of the Alcazar of Seville. Emplacement, foundations and former walls.}

\author{
Miguel Ángel Tabales Rodríguez ${ }^{(* *)}$, Pedro Gurriarán Daza ${ }^{(* *)}$
}

\section{RESUMEN}

La realización de diferentes excavaciones arqueológicas y estudios murarios en los últimos años en el alcázar de Sevilla han permitido clarificar el proceso de obras que se desarrolló durante el siglo XI y supuso el punto de arranque para la erección de uno de los mayores complejos militares y palatinos del período andalusí. Este trabajo describe el proceso, desde el planteamiento inicial de las obras hasta la terminación de las torres y lienzos, con especial énfasis en el replanteo y la ejecución de los cimientos. Se han obtenido dataciones absolutas que permiten, superadas las polémicas tradicionales sobre su cronología, definir un cronotipo arquitectónico extrapolable o comparable a partir de ahora con otros casos aun por investigar del mismo período.

Palabras clave: Taifa; emplecton; sillería; cimientos.

\section{ABSTRACT}

The different excavations carried out and the studies of the walls undertaken during the last few years at the Alcazar of Seville have made it possible to clarify the course of the works being carried out during the $11^{\text {th }}$ century and implied the starting point for the construction of one of the biggest military and palace complexes from andalusi period. This work describes the process, from the initial design of the works until the completion of the towers and sections, with special emphasis on the setting-out and the execution of the foundation. Absolut dates have been achieved which allows, once traditional controversy on its chronology has been overcome, to define the architectural chronotype extrapolated or comparable from now on to other cases to be studied from the same period.

Keywords: Taifa, emplekton, ashlar stone, foundations.

(*) El presente trabajo se inscribe dentro del Proyecto de Excelencia del Plan Nacional: "Sistematización Cronológica del Real Alcázar de Sevilla. Dataciones Absolutas y Gestión de la Información Mediante SIG y BIM Arqueológicos”. (HAR2017-85182-P)

$\left({ }^{* *}\right)$ Dr. Arqueólogo. Profesor titular. Depto. Construcciones Arquitectónicas 2. ETSIE. Universidad de Sevilla (España).

(***) Dr. Arquitecto. Yamur. Arquitectura y Arqueología S.L., Málaga (España).

Persona de contacto/Corresponding author: tabales@us.es (Tabales, Miguel Ángel)

ORCID: https://orcid.org/oooo-0002-9884-7407 (Tabales, Miguel Ángel); https://orcid.org/oooo-00o3-0877-3617 (Gurriarán, Pedro)

Cómo citar este artículo/Citation: Miguel Ángel Tabales Rodríguez, Pedro Gurriarán Daza (2021). La construcción del Alcázar de Sevilla. Replanteo, cimentaciones y murallas fundacionales. Informes de la Construcción, 73(563): e40o. https://doi.org/10.3989/ic.78484

Copyright: (C) 2021 CSIC. Este es un artículo de acceso abierto distribuido bajo los términos de la licencia de uso y distribución Creative Commons Reconocimiento 4.0 Internacional (CC BY 4.0). 


\section{INTRODUCCIÓN}

La bibliografía científica sobre edificaciones de al-Andalus está repleta de comentarios y anotaciones parciales sobre los modos y técnicas de cimentación y puesta en obra por los alarifes de las construcciones monumentales. Esta prolífica realidad contrasta con la falta de definición y seriación, lo cual no es más que el resultado de la ausencia de estudios arqueológicos y arquitectónicos en profundidad que puedan garantizar conclusiones precisas en la mayoría de las fortificaciones, medievales en general e islámicas en particular. Así, elementos como basamentos, muros, torres, materiales, etc...son motivo de reflexiones tecnológicas cuya base cognitiva refleja de facto notables faltas de precisión o dudas en las cronologías y en la identificación de los procesos originales. Y el desconocimiento es prácticamente completo si intentamos profundizar en aquellos aspectos que tratan en concreto del planeamiento de las obras, su replanteo, la manipulación y acondicionamiento del terreno y, finalmente, la ejecución de los cimientos.

Haciendo una revisión general a modo de estado de la cuestión, sabemos que desde el mismo siglo VIII la diversidad de soluciones en las murallas, fruto de las distintas tradiciones en la Península, se tradujo en el empleo coetáneo de diferentes modalidades de mampostería, sillarejos encintados, zócalos de mampostería bajo tapias, etc...por lo que suponemos que el acondicionamiento previo y los fundamentos serían igualmente diversos. En las fábricas califales cordobesas de cantería se empleaba un aparejo de soga y tizón en el que el número de tizones por cada soga fue incrementándose con el tiempo, así como su esbeltez. Estos tizones eran utilizados casi exclusivamente a nivel de cimientos en las primeras hiladas, siendo las murallas macizas de cantería (1). El desarrollo e incremento de las fortificaciones en tapial a partir del siglo XI generalizó otro tipo de soluciones en las que igualmente se observan diferencias regionales en cuanto a técnica, estructura y materiales (2). En este tipo de fábricas en ocasiones, los cajones se cimientan directamente sobre el terreno, pero es común encontrar zócalos pétreos con una alta resistencia que aíslan del suelo y sirven como base regularizada de replanteo.

En el caso del alcázar de Sevilla, se recurre de nuevo a las murallas de tres hojas con paramentos de sillería reutilizada, aunque isódoma, y un núcleo de tierra prensada que reflejan, ya con mucha distancia en el tiempo, los principios constructivos tardoantiguos y bizantinos popularizados por Flavio Vegetius, quien abogaba por este sistema como el más efectivo en una muralla. El sevillano es un caso en el que el espesor de dicho emplecton se aleja mucho de los 20 pies recomendados por el bizantino, ya que aquí apenas son tres.

Visto lo visto, aspirar a entender una teoría de la cimentación andalusí que se distinga de otras tradiciones y que trascienda en algo los principios romanos o bizantinos es hoy en día poco realista. Sirvan las siguientes páginas sobre el caso del primer recinto del alcázar de Sevilla, no obstante, para caracterizar e interpretar constructivamente un ejemplo de cierto interés histórico, al situarse cronológicamente en un momento en el que los cambios de todo tipo en la poliorcética peninsular se hicieron patentes (Figs.1 y 2). Se definirán tipologías constructivas generales, que engloben tanto cimentaciones como aquellos alzados que hayan podido ser estudiados (tabla 2).

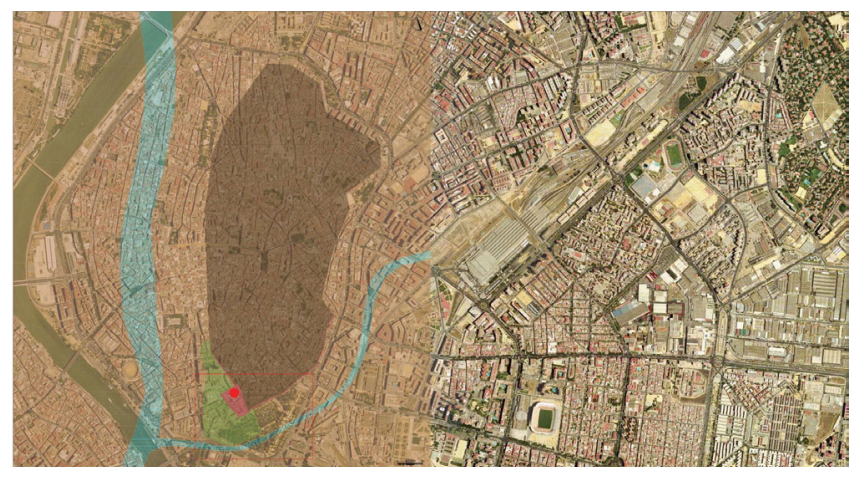

Figura 1. La ciudad de Sevilla en el siglo XI e inicios del XII. Al Sur la ubicación de los recintos I y II del alcázar, embrión del posterior alcázar almohade.

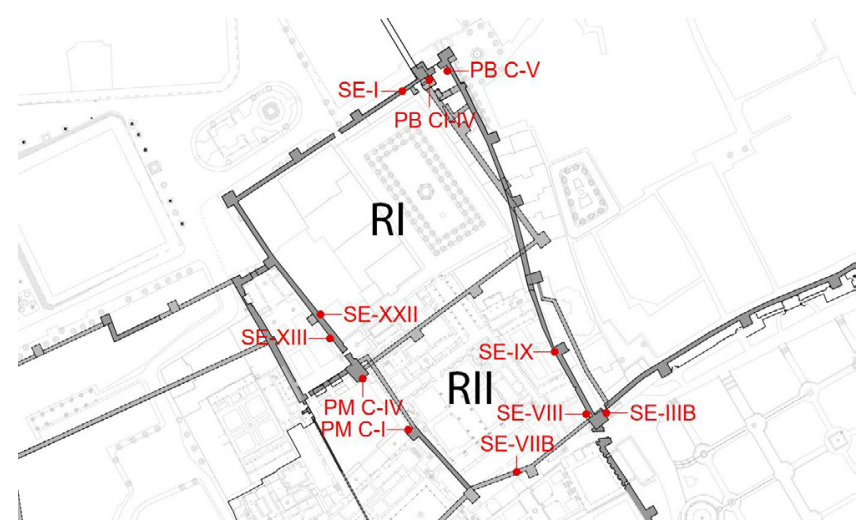

Figura 2. Ubicación de sondeos arqueológicos en la base de las murallas de los dos primeros recintos del alcázar de Sevilla.

\section{ANTES DEL ALCÁZAR. LA TOPOGRAFÍA URBA- NA PREVIA}

Las excavaciones arqueológicas realizadas en el sector del alcázar, Catedral y Archivo de Indias dibujan para el siglo XI un panorama novedoso y ciertamente trascendente para la comprensión de la ciudad antigua y su posterior redefinición en época almohade. Supone sin duda este momento una inflexión en la dinámica urbana pues confluyen dos hechos complementarios de naturaleza distinta que se dieron cita para permitir la expansión del poblamiento hacia el sector meridional de la ciudad, fuera de los límites del caserío altomedieval. Nos referimos, por un lado, al revulsivo que supuso la consolidación de la dinastía abbadí en pleno siglo XI y con ella el crecimiento del número de habitantes, cuestión claramente reflejada en las excavaciones del sector Norte y Sur de la ciudad y, por otro lado, a la dinámica de alejamiento del cauce del río hacia su actual posición, como delatan las necrópolis localizadas al Oeste de la Catedral y Archivo de Indias, proceso que posibilitó la colonización de zonas antes impracticables.

A la hora de definir el paisaje previo a la construcción del alcázar debemos vincular edificaciones y cotas de uso. Nos imaginamos una ciudad tardocalifal con un límite urbano en transgresión hacia el sur, con cambios de cota abruptos, donde las necrópolis, basureros, alfares y la misma zona de culto cristiano del Patio de Banderas iban cediendo sitio a viviendas y calles que a su vez mejoraban progresivamente su saneamiento mediante una red de alcantarillado de calidad. Así, el 
lugar que luego sería elegido para levantar la fortaleza abbadí, se encontraba urbanizado de manera abigarrada, siendo su organización ciertamente irregular al adaptarse a desniveles mucho más acusados que en la actualidad. Sin límites definidos, dicha urbanización, de la que no se conocen amurallamientos que pudieran contenerla (cosa que no podemos descartar), fue sometida a un proceso de enajenación parcial mediante el cual se procedió al derribo selectivo de los edificios situados en torno al Patio de Banderas a fin de levantar el primer alcázar. No advertimos un proceso similar en el entorno; es decir, las casas del barrio situadas bajo la Catedral, Archivo de Indias, Montería, Contratación, etc... perduraron más de un siglo hasta su sustitución por los palacios almohades y los diferentes recintos de la enorme alcazaba de los siglos XII-XIII. En otras palabras, en modo alguno el alcázar se levantó en un espacio extramuros deshabitado, sino que sus murallas se alzaron en medio de un barrio vivo que siguió rodeándolo de igual modo que en épocas pasadas sucediera con las fortalezas emiral, primero y califal después (Fig.3).

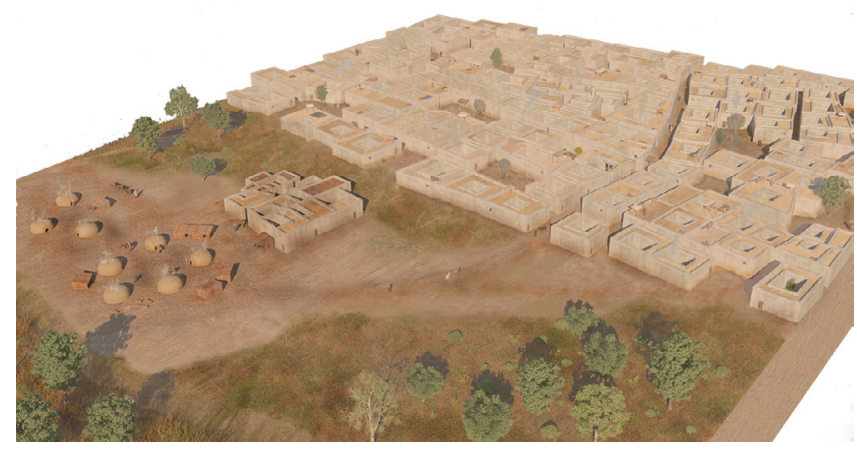

Figura 3. Recreación de los barrios ubicados en el sector meridional de Sevilla, localizados bajo el Alcázar, Archivo de Indias y Catedral. (Reconstrucción virtual de Jesús García a partir de hipótesis de M.A. Tabales).

Se levantaría inicialmente un primer recinto cuadrangular de aproximadamente una hectárea, del que hoy se conservan los lienzos y torres de los lados Norte y Oeste, para, a continuación, duplicar el espacio hacia el sur con un segundo recinto, del que hoy se conserva sólo su lado oriental. Un tercer recinto fue construido hacia el Oeste poco después en torno al Palacio de la Contratación. Se conservan en la actualidad la puerta de acceso, actual Puerta de Abdel Aziz en la Avenida de la Constitución y la torre poligonal y lienzos anexos. Cinco hectáreas finales divididas en tres recintos posiblemente diseñados en conjunto, pero claramente erigidos sucesivamente en un corto tiempo, desde las últimas décadas del siglo XI hasta mediados del siglo XII.

\section{ADECUACIÓN DEL SOLAR DE OBRA}

Imaginemos, por tanto, una operación arquitectónica excepcional mediante la cual se elige un sector habitado y se derriba un buen número de viviendas; todas las que coincidirán con el emplazamiento de las murallas del alcázar, y algunas más en la zona occidental que ocupará el gran palacio. La demolición en esos casos será completa y normalmente a ras de pavimentación o inmediatamente por debajo. En esos puntos se recuperará todo el material constructivo para ser reutilizado más tarde procediéndose a echar una capa de rellenos de limpieza en los que no abunda dicho material constructivo. El esfuerzo no fue menor ya que lo cómodo hubiera sido derribar las casas y apisonar los escombros. Si esto no se produjo así fue, entendemos, porque era imprescindible mantener cotas similares a las de las viviendas circundantes o interiores al alcázar, así como a sus calles, cosa imposible si se hubieran acumulado los escombros pues en ese caso el nivel de suelo hubiera subido notablemente en el interior.

Esto no debe obviarse pues delata un esfuerzo de extracción, desplazamiento y lógico vertido en algún otro lugar de la ciudad o de su perímetro, previo traslado de los escombros, cosa nada habitual. Es posible que gran cantidad de ellos se usara para los acuñados intersticiales de los sillares de la muralla, así como en su emplecton interno.

La preparación del terreno previo a la apertura de las zanjas fue minuciosa ya que se seleccionaron tierras relativamente limpias eliminándose cascotes de mediano y gran tamaño con las que se rellenaron las irregularidades y espacios entre muros con un espesor irregular, aunque raramente superior a unos decímetros. Es lo que hoy llamaríamos un acondicionamiento a nivel del terreno. Esto permitió mantener en uso algunas casas, calles y adarves del Patio de Banderas e incluso posibilitó la mejora del alcantarillado y la reforma de algunas casas. Toda la superficie acondicionada se mantuvo a la cota $12 \mathrm{msnm}$ con la excepción de la esquina noroeste, en la que se construiría la zona noble del palacio, donde sí se mantuvo el desnivel previo con lo que, desde entonces y hasta hoy, ese sector mantiene una altura bastante superior a la del resto del alcázar. Un caso aparte es el límite sur de la muralla, donde existía un desnivel previo no suavizado desde la época romana donde, o bien se aprovechó una estructura previa o bien se produjo una sustitución de murallas.

Durante las excavaciones del Patio de Banderas se detectaron varias fosas de expolio practicadas a distintos niveles. Como consecuencia de su apertura fueron extraídos un número considerable de bloques de piedra, mampuestos y ladrillos pertenecientes al almacén portuario romano y al hipotético cenobio tardoantiguo. Es probable que algunos fueran empleados en la construcción de las murallas, pero lo cierto es que los módulos de sillería romana y visigoda no se aprecian en esta de manera rotunda. Sí se advierten piezas pertenecientes al edificio tardoantiguo en los basamentos del barrio (mesas de altar, bases de tenante con huecos para reliquias, sillares, etc...) (Fig. 4).

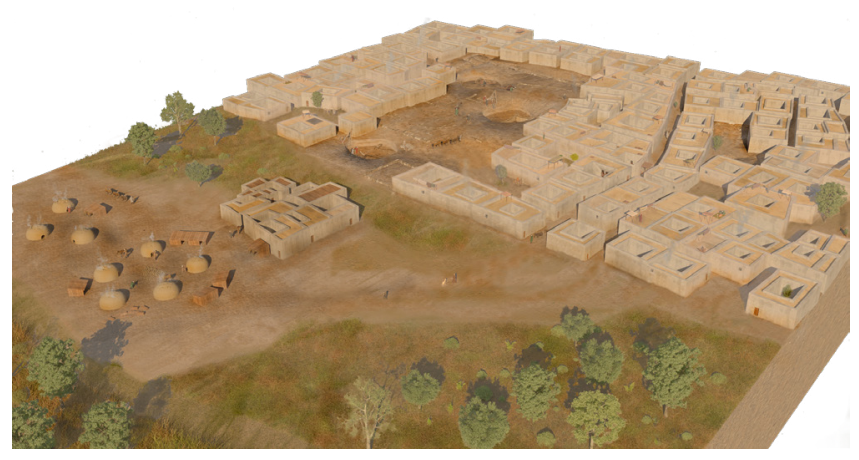

Figura 4. Derribo de edificios a mediados del siglo XI y apertura de zanjas de expolio. (Reconstrucción virtual de Jesús García a partir de hipótesis de M.A. Tabales). 
Pensamos pues que durante la construcción del alcázar gran parte de las estructuras domésticas del barrio del Patio de Banderas permanecieron en pie y que sólo tras algunos años de convivencia con las nuevas murallas y el gran palacio del lado oeste, se procedió a su derribo y a la apertura de grandes fosas, cuyo material de acarreo serviría para la construcción de las estructuras del segundo y tercer recinto (Fig. 5).

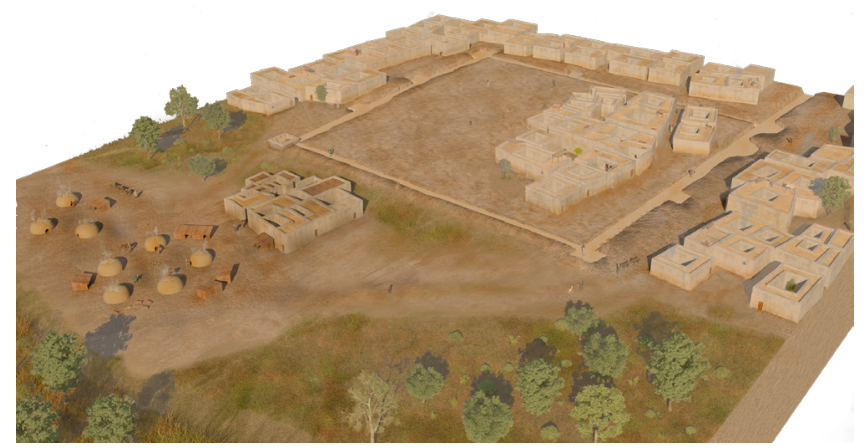

Figura 5. Apertura de zanjas de cimentación y preparación del cimiento del primer recinto del alcázar a mediados del siglo XI (Reconstrucción virtual de Jesús García a partir de hipótesis de M.A. Tabales).

\section{CIMENTACIONES}

Sobre el terreno nivelado se procedió a la apertura de zanjas para introducir los fundamentos (3). Desconocemos el sistema empleado en los laterales oriental y meridional pues sus muros han desaparecido, pero en los lienzos occidental y septentrional se han podido realizar un total de nueve sondeos estratigráficos que permiten comprender relativamente bien el proceso. De ellos, cinco fueron practicados en el interior y cuatro en el exterior.

La operación debió realizarse al unísono trazándose una zanja longitudinal de entre cuatro y cinco metros de espesor y una profundidad variable según la zona. En el lado Norte (SE I) se advierte cómo se trazó la zanja en forma de artesa. La profundidad de la fosa era de tres metros. Los dos primeros fueron rellenados empleando para ello tierra compactada con una pequeña proporción de cal; ello generó una base resistente sobre la que superponer las dos primeras hiladas de sillares previos a la caña de la muralla, separados ambos por una ligera zapata sobresaliente unos centímetros de la base. De este modo la base de la zanja tenía un espesor de cuatro metros que se ampliaban a cinco, dos metros arriba en la base de la zapata de piedra, para, finalmente, ya bajo la superficie, ampliarse a 5,50 $\mathrm{m}$ de zanja y 1,95 $\mathrm{m}$ de estructura pétrea. En definitiva, una base de piedra cercana a los dos metros de espesor dentro de una fosa de algo más de cinco (Fig. 6).
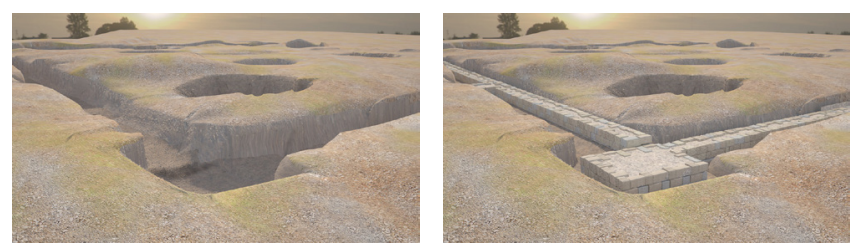

Figura 6. Proceso de apertura de fosas de cimentación para la muralla y primeras hiladas adaptándose al desnivel del terreno. (Reconstrucción virtual de Jesús García a partir de hipótesis de M.A. Tabales).
En este lado septentrional la muralla se situó a eje, centrado sobre la zanja de cimentación, manteniendo la escarpa como base de la nivelación sobre la que ubicar la caña de la muralla, ampliándose hacia el oeste, donde el terreno descendía, a una hilada más, corrigiendo así el declive topográfico y añadiendo nuevas zapatas sobresalientes (Tipo 1) (4) (Fig. 7)

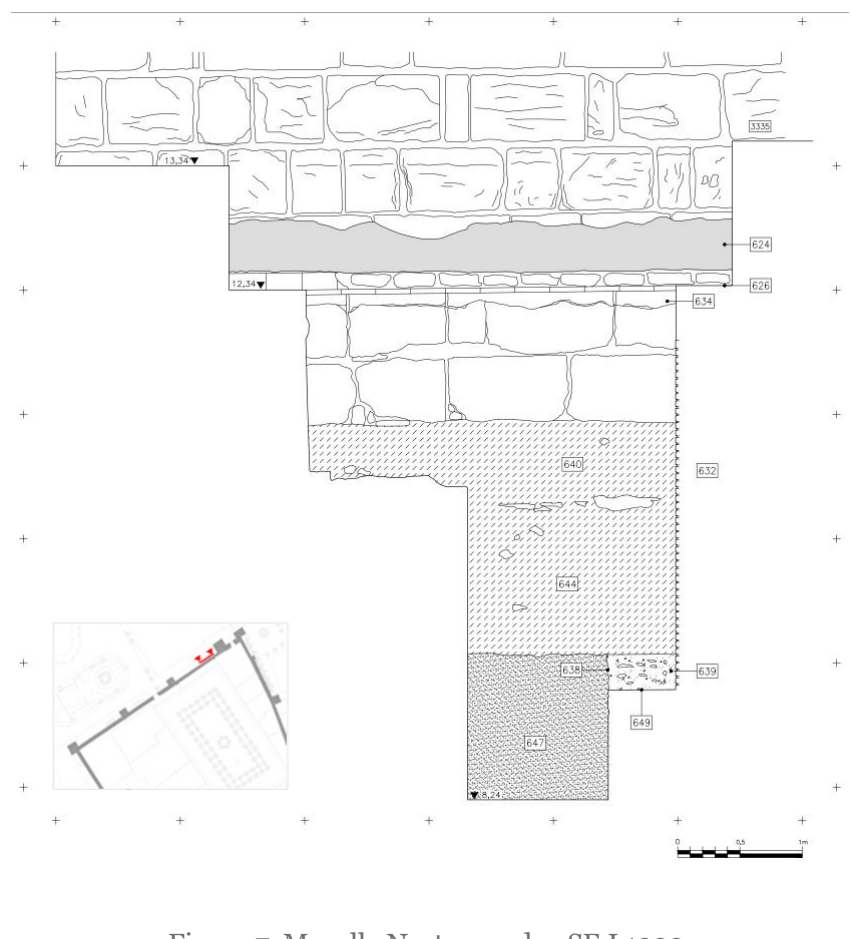

Figura 7. Muralla Norte: sondeo SE I 1999.

El lienzo occidental es ligeramente distinto al septentrional, pues tuvo que absorber declives mayores de la topografía, lo cual provocó un acomodo a las circunstancias que hemos tenido la fortuna de documentar tanto al interior como al exterior. En este caso, la fosa era más profunda pero un metro más estrecha, pues no superaba en su punto más amplio los cuatro metros de espesor. La profundidad de la losa era similar, al igual que la disposición de las dos primeras hiladas de piedra de la zapata, si bien aquí cada una de ellas formaba un escarpe distinto (dos en total) antes de dar paso al espesor homogéneo del muro. En definitiva, el lado oeste repartía las cargas piramidalmente, algo mejor que el lado norte. Por otro lado, la diferencia fundamental de este muro con respecto al septentrional estribaba en su desajuste respecto a la zanja pues este se ubicaba desplazado al interior, donde la fosa apenas sobresalía $15 \mathrm{ctms}$ de la estructura pétrea, mientras que al exterior el cimiento sobresalía dos metros (Tipo 2) (5) (Figs. 8 y 9).

Entendemos que esta diferencia se explica por la necesidad de corregir el declive topográfico, dispuesto en sentido transversal al de la muralla, o dicho de otro modo, como el lienzo norte discurría hacia el Oeste en el sentido de la pendiente, tanto fosa como muralla estaban a eje, mientras que la muralla oeste, al dirigirse el declive hacia el oeste, se hizo necesario reforzar la base de cimentación en esa dirección, equilibrando los empujes gravitacionales con un mejor asiento en el lado más débil.

Más comprometida aún, en la topografía, era la cimentación de la torre suroccidental del primer recinto, situada en el Pa- 


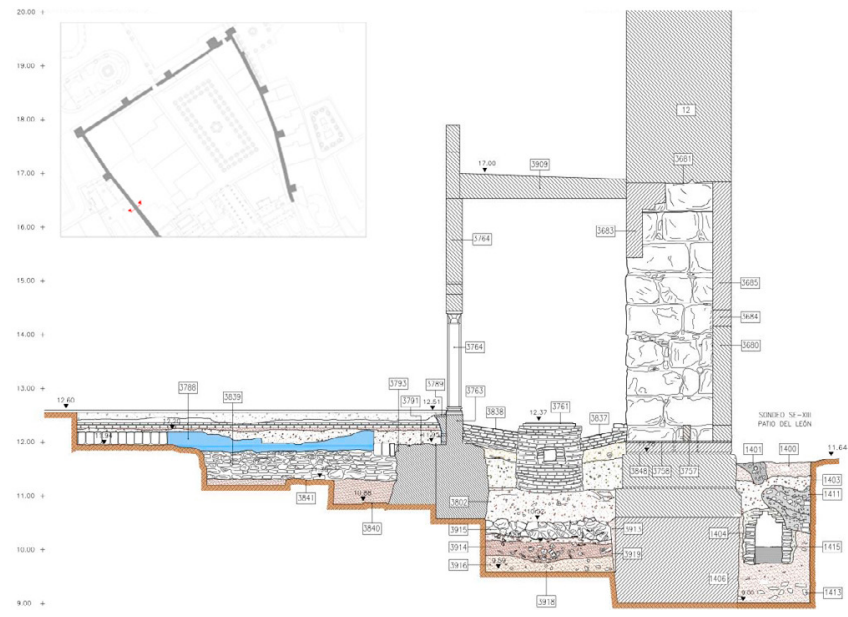

Figura 8. Muralla occidental: casa 7/8 del Patio de Banderas; sondeo SE XXII, 2013. Sección Este-Oeste.
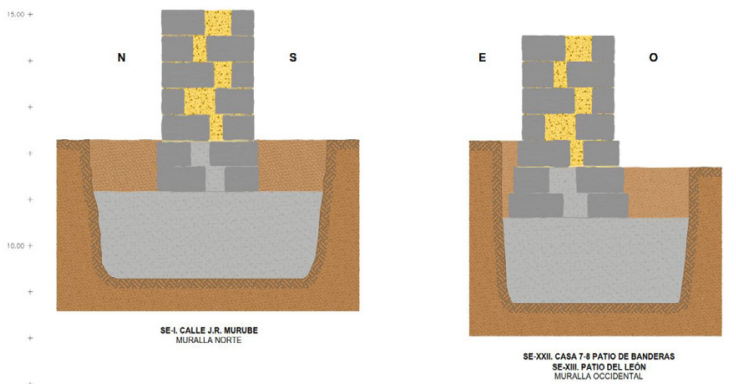

$\square$ LOSA DE CAL

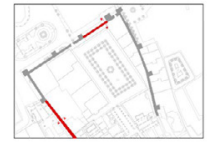

Figura 9. Secciones comparadas de los dos cimientos de las murallas Norte y Oeste (Tipos 1 y 2, respectivamente).

tio de la Montería, pues allí debía corregirse la suave pendiente hacia el oeste y la un más aguda pendiente hacia el sur (Tipo 3 en esta torre y las siguientes). La excavación nos permitió observar cómo el cimiento de la torre, algo más profundo que el lienzo, ajustaba los bloques pétreos sobre la losa

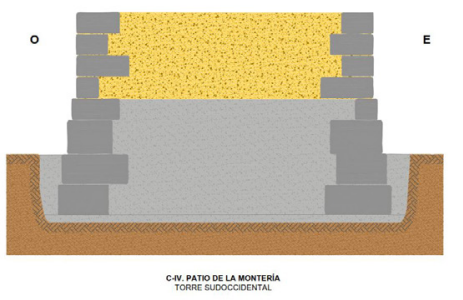

Figura 10. Esquema de la cimentación de la torre suroccidental del recinto primitivo (Tipo 3 ). de tierra mejorada al extremo, ya que ese preparado apenas se configuraba como una pequeña suela aislante de $20 \mathrm{~cm}$. Su característica principal era, no obstante, la disposición de las cuatro primeras hiladas en escarpe poco pronunciado, generando una pirámide escalonada de dos metros de altura como base para el desarrollo de la torre, eso sí, quedando vistas y enlucidas al exterior las dos hiladas superiores y por tanto dejando las dos primeras, como en el resto de los muros, bajo rasante. De este modo la torre, cuyos lados eran de 4,5 $\mathrm{m}$, se ampliaba en profundidad hasta disponer de lados de 5,60 $\mathrm{m} \mathrm{y}$ un área de base de 31,36 m cuadrados (6) (Fig. 10).

El sistema, como vemos, es en extremo inteligente a la vez que sencillo ya que se adapta a la topografía previendo con claridad los problemas derivados de la irregularidad del terreno (Fig. 11). Caso aparte son los basamentos de las distintas torres; y es que cada una de las cinco conservadas tiene una factura diferente. Así, la más oriental de todas (situada al Este de la puerta actual al Patio de Banderas), dispone de un visible y pronunciado talud en su base. Es un caso único en todo el recinto y, de hecho, aunque la isodomía general de lienzos y torres delata una única factura para toda la muralla, en esta torre el número de medios tizones que recuerdan lejanamente al estilo califal es más numeroso que en el resto de la fábrica. Es como si, entre todos los alarifes de la obra, el responsable de este tramo tuviera una formación cordobesa o estuviera familiarizado con esta típica solución omeya.

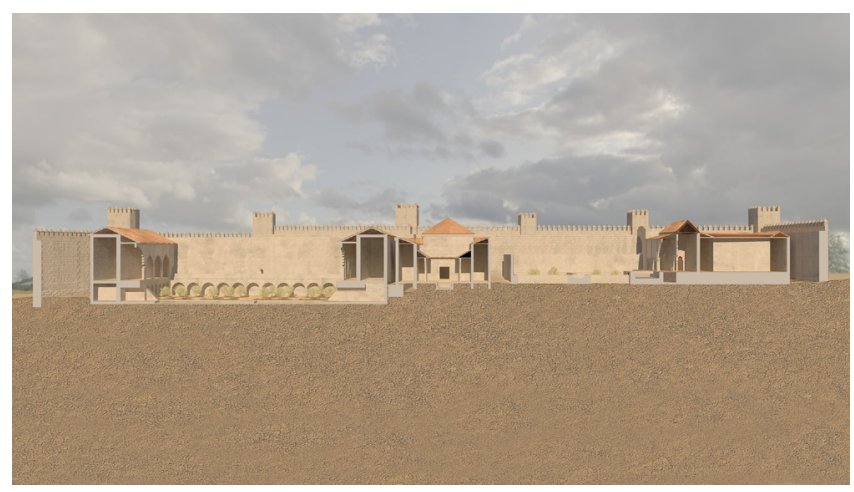

Figura 11. Declive del terreno que debió salvar la construcción del primer recinto (derecha), y sobre todo del segundo recinto (sector izquierdo de la imagen). (Reconstrucción virtual de Jesús García a partir de hipótesis de M.A. Tabales).

La siguiente torre del lienzo Norte (al oeste de la puerta al Patio de Banderas) y la primera de las torres del flanco Oeste (única conservada de dicho flanco, situada junto a la Puerta del León), así como la ya referida torre suroccidental (en el Patio de la Montería), elevan el número de escarpas sobre la general de la muralla, configurándose mediante basamentos piramidales de cuatro hiladas desde la losa de cimentación. Se labraron pues como verdaderos estribos de los lienzos sin que para los constructores tuviera mayor relevancia que parte de dichas zapatas fueran o no visibles.

Finalmente, la torre noroccidental (frente al Archivo de Indias) se configura desde la base como un cubo paralelepípedo sin escarpa, zapata o resalte alguno. No sabemos cuál es la razón de esa singularidad, aunque sospechamos que en este sector se produjo un fallo durante la construcción del alcázar que obligó a replantear la ejecución sobre la marcha. En efecto, en la esquina noroeste del alcázar, frente a la Plaza 


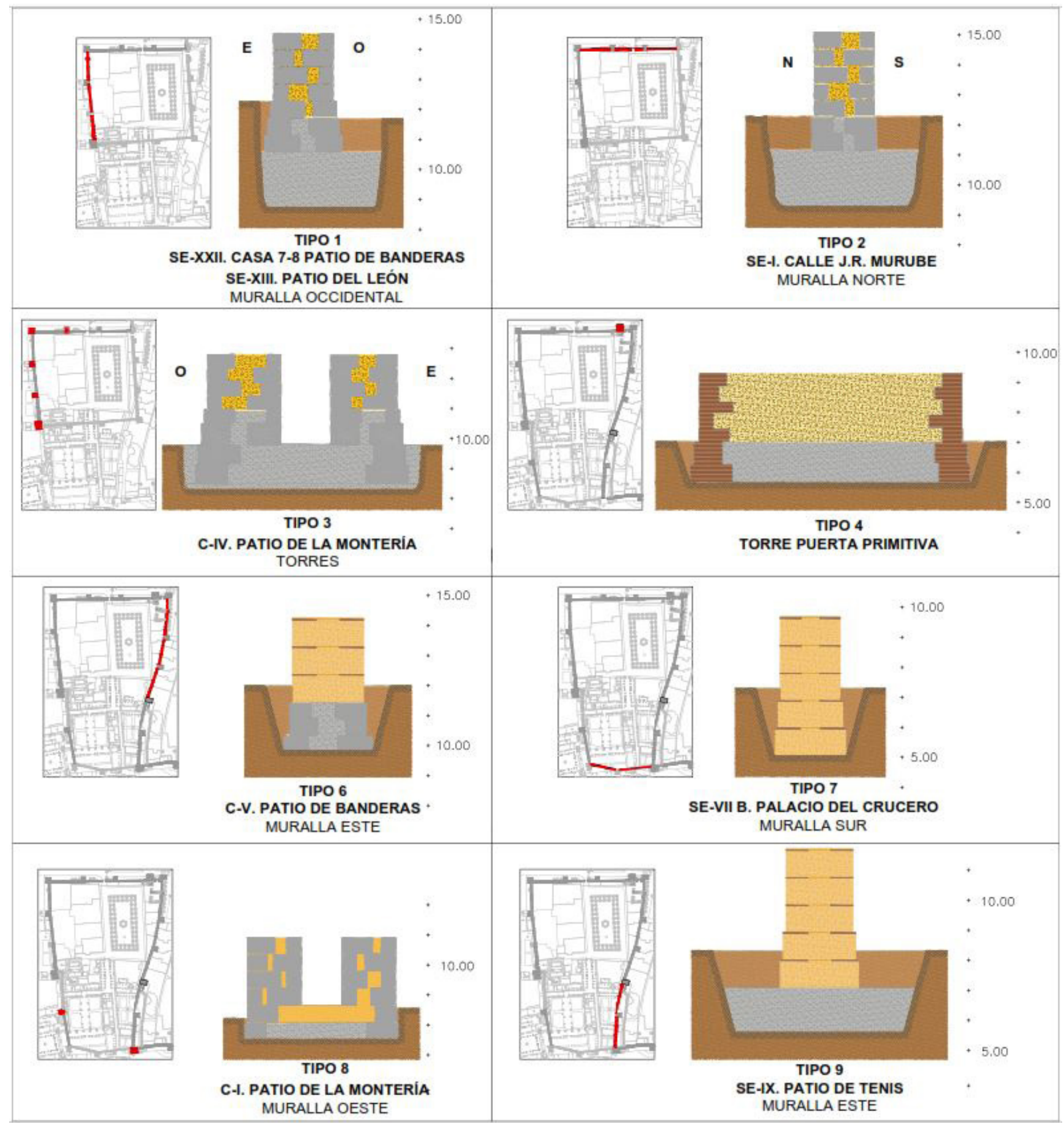

Figura 12. Esquema comparativo de las tipologías de las cimentaciones de los recintos I y II del Alcázar.

del Triunfo, se advierte en su parte inferior una ruptura de la homogeneidad de las hiladas bajo la escarpa, corregida mediante una hilada en forma de cuña. Posiblemente a causa de un asiento, el terreno cedió veinte centímetros hacia el Oeste y la reparación consistió en introducir una hilada supletoria que permitiría generar una superficie nivelada desde la cual, ahora sí, enderezar el ritmo de las hiladas.

Con la excepción de los frentes Norte y Oeste ya citados, levantados íntegramente en sillería, el resto de murallas de los dos primeros recintos del alcázar, previos a la gran ampliación almohade iniciada en 1172 , se ejecutaron mediante la técnica del tapial, con la excepción del lienzo occidental del segundo recinto que es pétreo, la torre suroriental del segundo recinto que es pétrea en su base, y las torres del lado norte del tercer Recinto cuyo aspecto "actual" es de ladrillo encadenado con sillería a hueso. El uso de la piedra tiene un sentido propagandístico al usarse sólo en aquellos lienzos de ambos recintos que se abren al exterior de la ciudad en la zona del puerto mientras que el tapial, empleado en la cerca urbana, es la técnica empleada allí donde los muros del alcázar forman parte de las defensas urbanas.

El lado Este del primer recinto, que en teoría sustituye al original, situado en las inmediaciones, dispone de un pie de aguja de sillares y sillarejos irregulares tendente a las dos hi- 
ladas, sobre una amplia zapata del mismo material que sirve de base a la caña de la muralla, realizada en tapial (Tipo 6). Siendo este cimiento similar en la forma a la de los lienzos norte y oeste del primer recinto, se diferencia de estos, aparte de por su posterioridad estratigráfica, por su tosquedad, tanto a nivel morfológico como por el cuidado en la colocación de los bloques y en la dimensión de la zapata (7).

El lado oriental del segundo recinto, que es prolongación hacia el sur del citado lienzo, está conformado por murallas de tapial encadenado en su alzado visible (8) (Tipo 9). Su peculiaridad principal es que este muro, datado en época almohade gracias al material cerámico de los sondeos VII y IX, es una reconstrucción de la muralla original de tapial simple, localizada debajo (9).

En síntesis, nada que ver con la cimentación del recinto primero en ninguno de los casos; la técnica, los materiales, el tipo de fosa, sus zanjas de cimentación difieren tanto de los muros fundacionales del alcázar como de los de la ampliación al Este de dicho recinto. Los materiales arqueológicos asociados y las dataciones responden a un período muy poco posterior al de aquel, pero, aun así, las técnicas constructivas empleadas y los esfuerzos de cimentación fueron distintos y podría decirse, más habituales o toscos que los originales.

Por su parte, la muralla meridional del segundo recinto, excavada en el pasaje de los Baños de Doña María, responde el mismo esquema que la del lado oriental; es decir, está realizada en tapial simple con dos cajones iniciales con sendas escarpas, sin zócalo alguno (Tipo 7). Se introduce en una fosa en forma de "V" con perfil más agudo que la del lado oriental. En este caso en su parte superior llega a superar el metro y medio de anchura a cada lado, lo que hace un total de cinco metros de ancho de fosa para introducir una muralla de algo menos de dos metros de espesor. A diferencia del lado oriental, aquí el primer cajón se asienta sobre la base de la fosa y no sobre una losa preparada más profunda.

Por último, la cimentación del lado occidental del segundo recinto, levantado en sillería, como el primero, ha salido a flote en la excavación del Patio de la Montería, situado en la cara norte de la única torre de flanqueo de dicho lienzo, hoy parcialmente conservada en el extremo oriental de la gran fachada del Palacio de Pedro I. El cimiento es el más atípico de los estudiados en las distintas torres de los dos recintos originales del alcázar pues no diferencia resalte ni escarpa alguna más allá de la primera hilada, que dispone de un ligero resalte (Tipo 8). La misma zanja es atípica pues se circunscribe al espacio de la estructura por lo que no tiene zanja lateral; en otras palabras, la torre ocupa el espacio íntegro de la pequeña fosa practicada. Aquí contamos con el primer pavimento externo, que se sitúa justo sobre la pequeña zapata dejando de manifiesto la simpleza y minimalismo del cimiento soterrado de la torre; nada que ver con la potencia, esfuerzo e inteligencia de las del primer alcázar (10).

En definitiva, en apenas dos recintos separados tan solo por algunos años, se materializan no menos de ocho modalidades diferentes de cimentación, si bien se engloban en cuatro categorías distintas, a su vez encuadrables en dos procesos bien diferenciados que dejan entrever diferentes intencionalidades y dominio de la técnica. Por lo que respecta a los materiales empleados no existe una diferencia clara entre dos zonas distintas por lo que no puede simplificarse en algo tan aparentemente lógico como el uso de la sillería para una fase antigua y el del tapial para una reciente. En ambos recintos se emplean tanto la piedra como el tapial. Es en el tratamiento de las fosas de cimentación, sus profundidades y el reparto piramidal de las cargas donde se aprecia una clara superioridad del primer recinto respecto al segundo (Fig. 12).

\section{MURALLAS Y TORRES. TÉCNICAS CONSTRUC- TIVAS}

La edificación del primer recinto es inseparable de la del tramo de muralla urbana del sector oriental, si bien este se realizó mediante técnicas diferentes, entendemos que al unísono de la cerca. En ese sector los restos rescatados en el interior de la muralla de flanqueo sur de la torre actual, sita en la casa $\mathrm{n}^{\circ} 16$ del Patio de Banderas (11), evidencian que, tanto lienzo como al menos una de las torres anexas a la puerta inicial, están labradas en tapia simple reforzada en la base mediante sillería reutilizada y en alzado con esquinas encadenadas con fábrica mixta (Tipo 4) (Fig. 13).

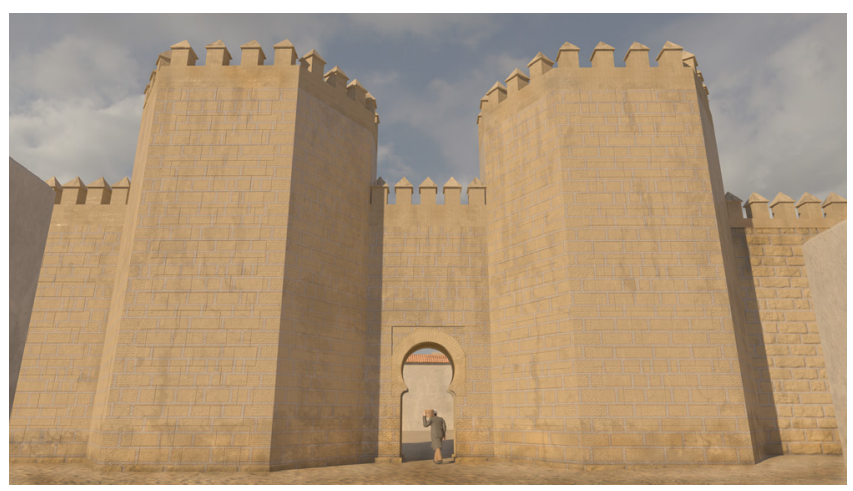

Figura 13. Reconstrucción de la puerta original del primer recinto, hoy bajo la casa 16 del Patio de Banderas. Su fábrica era de tapia encadenada con machos de aparejo mixto. (Recreación de Jesús García)

Por otro lado, las murallas Norte y Oeste del primer alcázar, hoy en pie, fueron levantadas en sillería sobre las hiladas de nivelación y escarpas antes citadas de tal modo que, con independencia de la posición de la escarpa, distinta en ambos lienzos, fue dispuesta de manera isódoma hasta una altura homogénea (Tipos 1 y 2) (Fig. 19). En el lienzo norte, como la escarpa era más alta, se elevaron 17 hiladas hasta el adarve mientras que, en el lado oeste al ser más baja, fueron 18 . El resultado fue el establecimiento de una nueva base de nivelación uniforme previamente a la construcción de parapeto y almenado, donde se emplearon materiales diversos para componer mediante una tosca fábrica mixta los remates de la coronación.

Lienzos y torres están construidos mediante tres hojas; los paramentos exteriores de sillería y el emplecton interior de tierra mejorada apisonada en tongadas (12). El espesor de los muros es de 1,9 m. (6 pies islámicos) y la distancia entre torres de 100 pies islámicos Las torres angulares son cuadradas de 25 pies de diagonal y el resto de 20 pies de diagonal, sobresaliendo 10 pies del lienzo de muralla. El recinto es un cuadrado de 300 pies de lado definiendo un área interior de $8.450 \mathrm{~m}$. cuadrados. Se levantaron 12 lienzos y 13 torres de $12 \mathrm{~m}$. de altura en 20-21 hiladas pétreas más el parapeto y el almenado de mampostería. Un recuento aproximado nos permite suponer que se utilizaron unos 37.00o sillares extraídos presuntamente de la muralla romana, cuya ubicación (tal vez por esto) desconoce- 


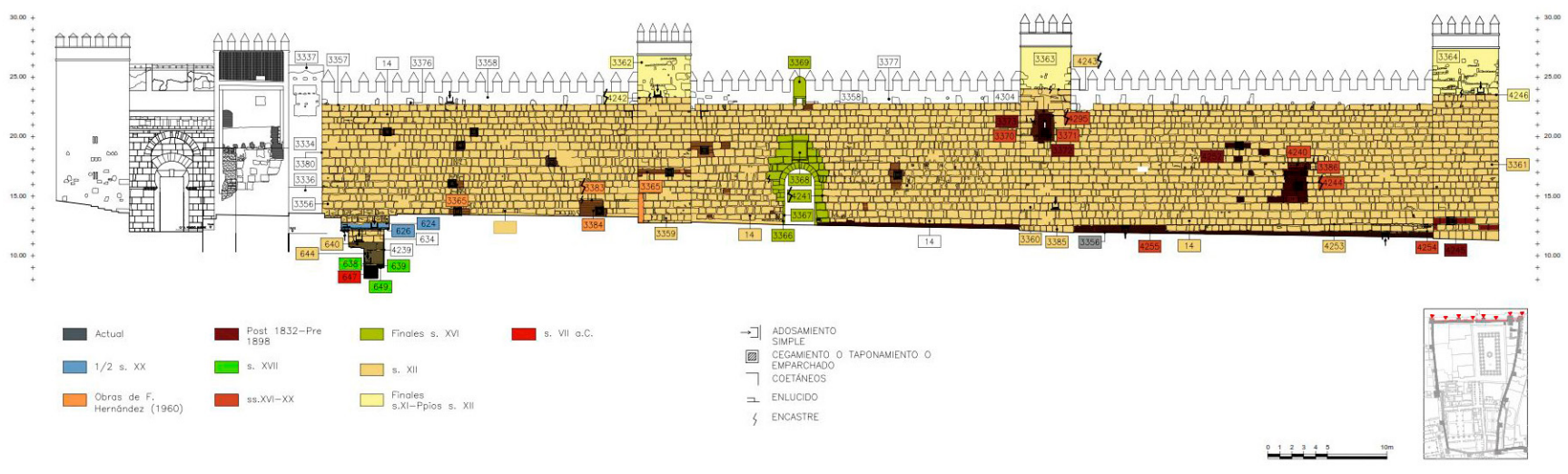

Figura 14. Alzado exterior de la muralla norte del primer recinto.

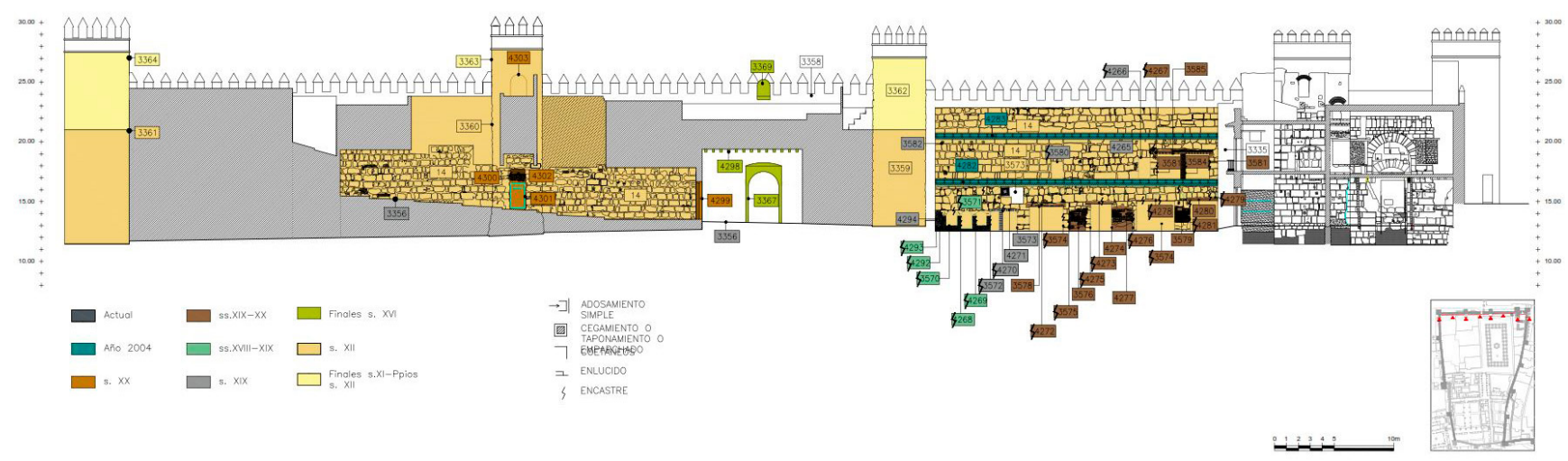

Figura 15. Alzado interior de la muralla norte del primer recinto.

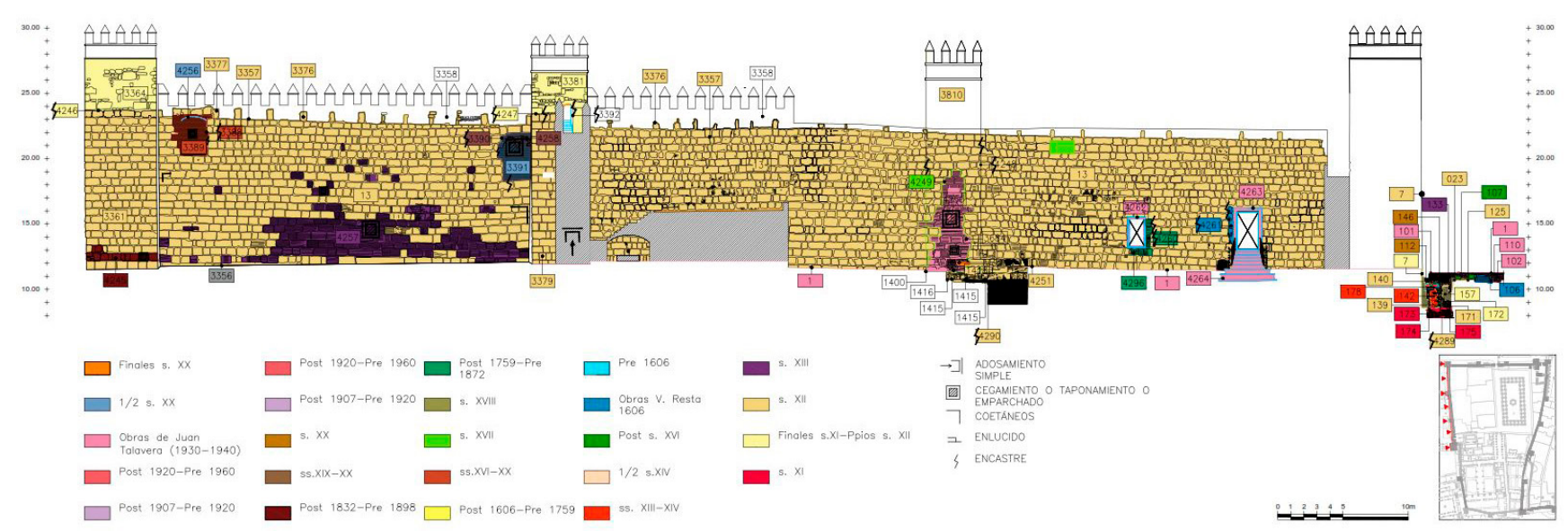

Figura 16. Alzado exterior de la muralla occidental del primer recinto.

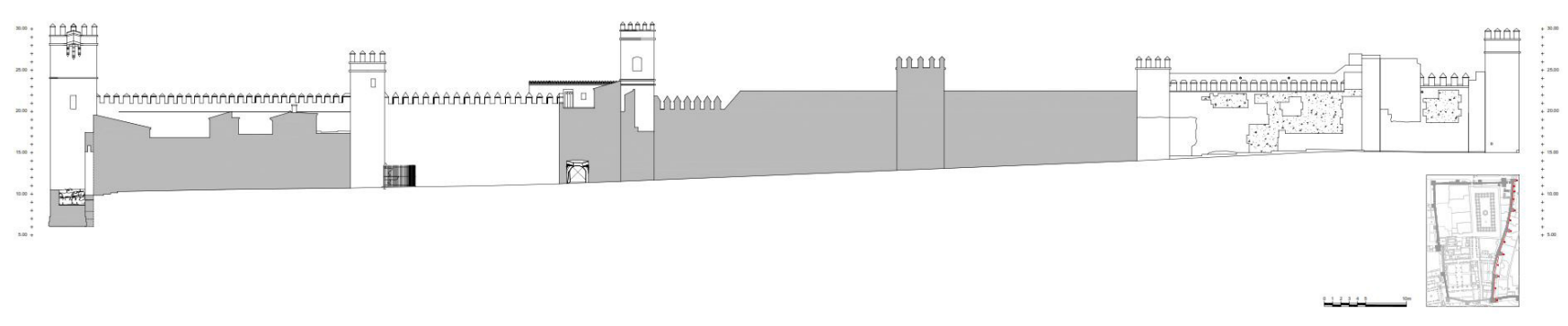

Figura 17. Lienzo oriental del alcázar. Recintos I y II. 
mos, aunque entendemos que discurriría por las inmediaciones. Estas cifras dan fe de la verdadera naturaleza del expolio ya que inevitablemente debieron desmontarse no menos de 400-500 m. lineales de muralla romana si es que esta se conservaba en altura similar (Figs. 14 a 17).

Con un peso aproximado de entre $150 / 200 \mathrm{Kg}$ por bloque y 2.500 metros cúbicos de mortero, la obra debió prolongarse varios años. No creemos que la población de Isbiliya en la segunda mitad del siglo XI pudiera sobrepasar los 15.00o habitantes dada su extensión por lo que la capacidad operativa y la mano de obra disponible, aunque se utilizara de algún modo el precario contingente militar disponible por entonces, nunca sería suficiente para que la construcción fuera rápida (Fig. 18).

La dimensión de los bloques empleados en los paramentos es variable si bien su altura es uniforme, de $0,52 \mathrm{~m}$, equivalentes al codo romano, delatando su procedencia. No están dispuestos a hueso como probablemente estuvieron en su disposición original, sino que están separados por llagas superiores a un palmo y tendeles de igual espesor, tomados con barro y cuñas latericias a base de fragmentos de besales romanos o ladrillos finos de cronología taifa. El aparejo bajo las escarpas y en cimentación es distinta al ser las juntas algo más finas y estar argamasadas con mortero de cal.

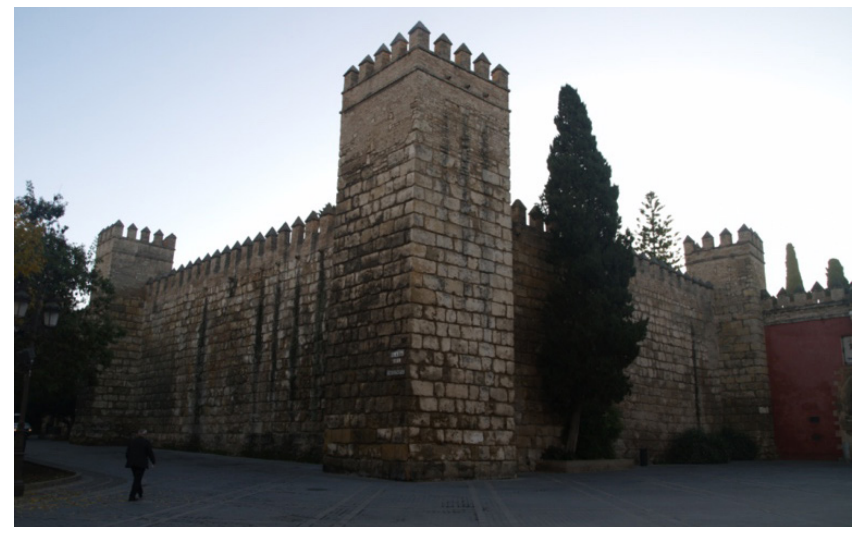

Figura 18. Muralla del primer recinto desde su ángulo noroccidental.

El material pétreo utilizado es variable si bien es la piedra alcoriza (biocalcarenita conglomerática) la que domina con un $75 \%$ del total aproximadamente, seguida por la roca ostionera del Puerto de Santa María con un 20\%, mientras que la arenisca, sobre todo en la puerta principal y otros materiales como el yeso, el pórfido rosa, el mármol blanco o la caliza, oscilan en torno al $5 \%$. La roca alcoriza, procedente del triángulo del Alcor, situado entre Alcalá de Guadaira y Carmona, ha sido analizada en el lienzo occidental de la muralla, aportando una resistencia a compresión igual a $40 \mathrm{Kg} / \mathrm{cm}^{2}$ o lo que es igual, $4 \mathrm{~N} / \mathrm{mm}^{2}$, lo que supone un valor algo menor a los registrados en muros similares en la mezquita de Córdoba, donde oscila entre los 70 y los $200 \mathrm{Kg} / \mathrm{cm}^{2}$ (Fig. 19).

Lo mismo sucede en el emplecton de la muralla; es decir, cimientos y escarpas están compuestos por argamasa de cal y cascotes de alta resistencia a compresión, mientras que en la caña del muro el núcleo está conformado por tongadas de tierra mejorada con cal y cascotes de muy baja resistencia. La resistencia total de la muralla se verá afectada principalmente por las hojas pétreas exteriores considerando el valor de la hoja interior insignificante, apenas un 19,2 kg/ $\mathrm{cm}^{2}$. Está compuesto por una

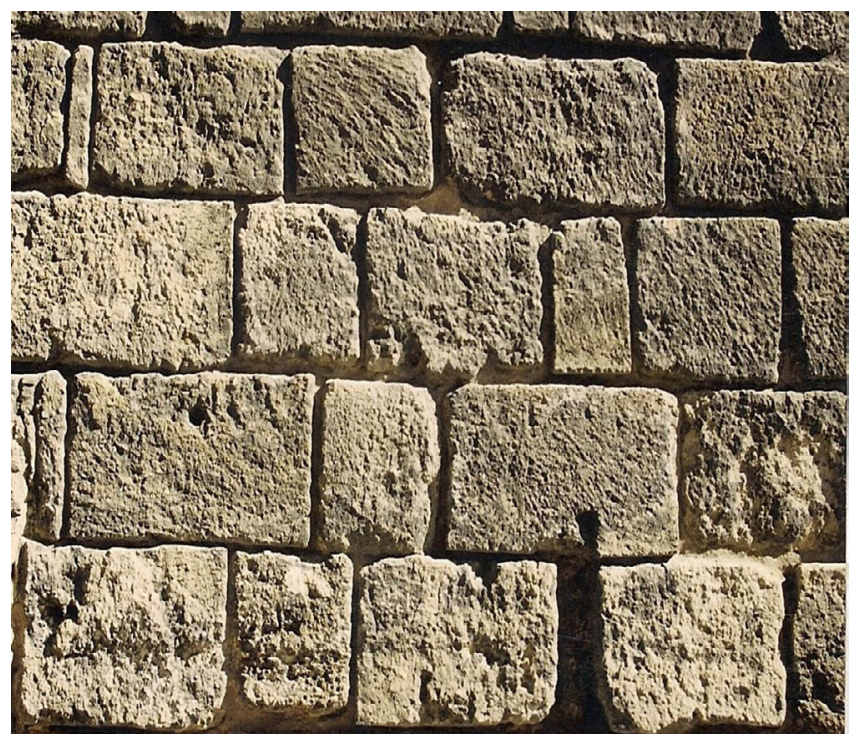

Figura 19. Hiladas de roca calcarenítica, mayoritarias en la construcción del alcázar.

cantidad abundante de cuarzo y calcita, siendo medianamente abundante las micas y arcillas, así como cenizas de obra y basurero, y en menor grado las dolomitas feldespatos y albitas.

El relleno está dispuesto en tongadas de un palmo, a veces algo menos. El índice de porosidad abierta de esta tierra mejorada con cal, a modo de tapial, es similar al habitual, cercano al 35\% y debajo de 50\%. La densidad real es de $2.53 \mathrm{gr} / \mathrm{cm}^{3}$, al igual que la densidad aparente, mientras que la porosidad accesible al agua es del $33.40 \%$. El origen de esta alta porosidad se debe a la presencia de finos de $\varnothing<0.063 \mathrm{~mm}$ (cal, calcita, minerales de la arcilla...) caracterizándose por poseer una elevada superficie específica con alta capacidad de absorción de agua; durante el amasado se utiliza una cantidad de agua para facilitar la trabajabilidad del hormigón. En nuestro caso, las medidas tomadas en la muralla occidental (a la altura de la Torre del León) el emplecton posee un intervalo de valores de porosidad algo inferiores a los habituales en las fábricas de tapia por lo que se puede considerar más bien como un mortero/hormigón de relleno con mediana-baja porosidad, lo que delata que se empleó relativamente poca agua y sin embargo se procedió a una elevada compactación mediante pisón (tabla 1).

Tabla 1. Comparativa de propiedades del emplecton con los rangos habituales para los tapiales andalusíes. Muestras tomadas durante la Intervención arqueológica en la casa 7/8 del Patio de Banderas, bajo la dirección de Cristina Vargas y M.A. Tabales, en 2016, y analizadas por Flores V., Alejandre, J. Blasco, F.J. y Martín del Río, JJ.

\begin{tabular}{|l|l|c|}
\hline PROPIEDADES & EMPLECTON & $\begin{array}{c}\text { INTERVALOS } \\
\text { HABITUALES }\end{array}$ \\
\hline $\mathrm{CaCO}_{3}$ (\%) & 38.6 & $12.6-50.9$ \\
\hline $\begin{array}{l}\text { Dosificación máxima en } \\
\text { cal (cal-árido en peso) }\end{array}$ & $1: 3$ & $1: 1$ a 1:10 \\
\hline Porosidad (\%) & 33.4 & $23.5-47.4$ \\
\hline Granulometría & $\begin{array}{l}\text { Muy alto \% de finos } \\
\text { y mala compacidad }\end{array}$ & -- \\
\hline $\begin{array}{l}\text { Resistencia a compre- } \\
\left.\text { sión (Kg/cm }{ }^{2}\right)\end{array}$ & 19.2 & $13.2-148.3$ \\
\hline Calidad & Baja & -- \\
\hline
\end{tabular}


El aparejo de la muralla es diferente en lienzos y torres por un lado y en la puerta principal por otro. Aquí los sillares, mayoritariamente de roca arenisca, pórfido rosa, ostionera y calcarenita, están unidos a hueso y tallados de manera cuidada con una superficie lisa y un diseño a soga y tizón irregular (Tipo 5). El grueso de la muralla y de las torres responde a un aparejo isódomo de sillares organizados a soga y tizón irregular, con algunas zonas donde abundan los medios tizones dispuestos a la manera califal y otras donde en sitios muy concretos se observan engatillados o formación de sillares mediante mampuestos ordenados (Fig. 20).

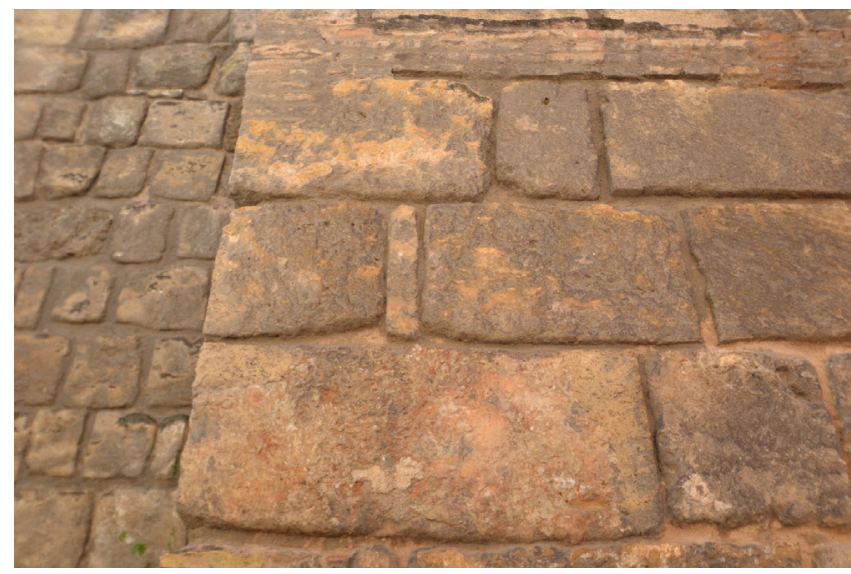

Figura 20. Hiladas de sillares a soga y tizón irregular con tizones y medios tizones esporádicos

La sillería atizonada, en la que destacan los medios tizones, está presente, aunque en rangos muy bajos si la comparamos con las ordenadas fábricas emirales y califales de los siglos IX y X (13). Son más abundantes en el lienzo Norte que en el Occidental y se recurre a tizones muy finos sobre todo en el extremo oriental del lienzo norte, lo que nos hace pensar en la posibilidad de que los alzados de la fortaleza fueran dirigidos por alarifes distintos, comenzándose tal vez los trabajos por la zona noreste con algún constructor cuya mentalidad estuviera muy mediatizada por la tradición cordobesa y rematándose por la parte suroccidental de manera más precipitada.

Las series continuas de sogas y tizones alternos en la misma hilada son igualmente predominantes en la cara norte mientras que en la occidental son no sólo menos abundantes, sino que el descuido de la horizontalidad y de la calidad de los bloques y el aparejo son evidentes. $\mathrm{Al}$ igual que con los medios tizones las secuencias completas de sogas y tizones alternos son muy abundantes en el lado Norte mientras que progresivamente se van perdiendo a lo largo del lienzo occidental para desaparecer casi por completo en el extremo suroccidental (Patio del León) donde además las hiladas están muy descuidadas en su horizontalidad y los bloques raramente aparecen completos siendo en general fragmentarios, abundando los tizones y sogas cortas. En ese sector incluso se descuida el más elemental solape, abundando la superposición de llagas. Existen incluso bloques muy altos que rompen la hilada y pasan a la siguiente. Un conteo básico del lado Norte exterior indica que las series de entre 10 y 16 piezas a soga y tizón alternas seguidas son abundantes, aunque lo son más las series de entre 5 y 8 , y sobre todo en el extremo este del lienzo. Por su parte en el lado occidental las series por encima de las 7 piezas son inexistentes, concentrándose en el extremo Noroccidental, mientras que en los dos lienzos de lado sur del lado occidental van desapareciendo, siendo muy raras las alternancias de más de 5 bloques.

En resumen, parecería que el lienzo Norte se edificó primero con la mejor calidad posible (Tipo 1), comenzando la obra por el extremo oriental, junto a la muralla urbana, y a medida que fueron erigiéndose las hiladas en dirección Oeste y luego Sur (Tipo 2), la técnica fue empobreciéndose por mala calidad de los bloques, mayor descuido en la nivelación de las hiladas y menor número de medios tizones y series largas de sogas y tizones. Es en esta parte occidental donde advertimos más piezas reutilizadas, fundamentalmente tambores de columnas y aras romanas, inexistentes en el primer tramo. Otra posibilidad es que, dada la continuidad de las hiladas y ausencia de interfacies evidentes a lo largo de la fábrica, la obra se dividiera en tramos distintos al cargo de alarifes de distinta calidad, siendo la parte norte ejecutada por algún constructor bien consciente de la técnica califal, al menos en el aparejo, mientras que en el lado oeste los constructores, o por prisa o por mala calidad de los materiales o por formación carencial en el manejo de la piedra, descuidaron más la ejecución (Figs. 21 y 22).

Como ya se dijo, los bloques pétreos utilizados en la erección de la muralla proceden de construcciones anteriores y se observan numerosos indicios del reaprovechamiento. En primer lugar, el deterioro de los bloques es apreciable; incluso podría decirse que han sido reutilizados en más de una ocasión dado el nivel de desgaste que reflejan tanto en superficie como en el aristado. Otra de las claves de la reutilización está en las huellas de izado de los bloques, aún visibles en un elevadísimo número. También
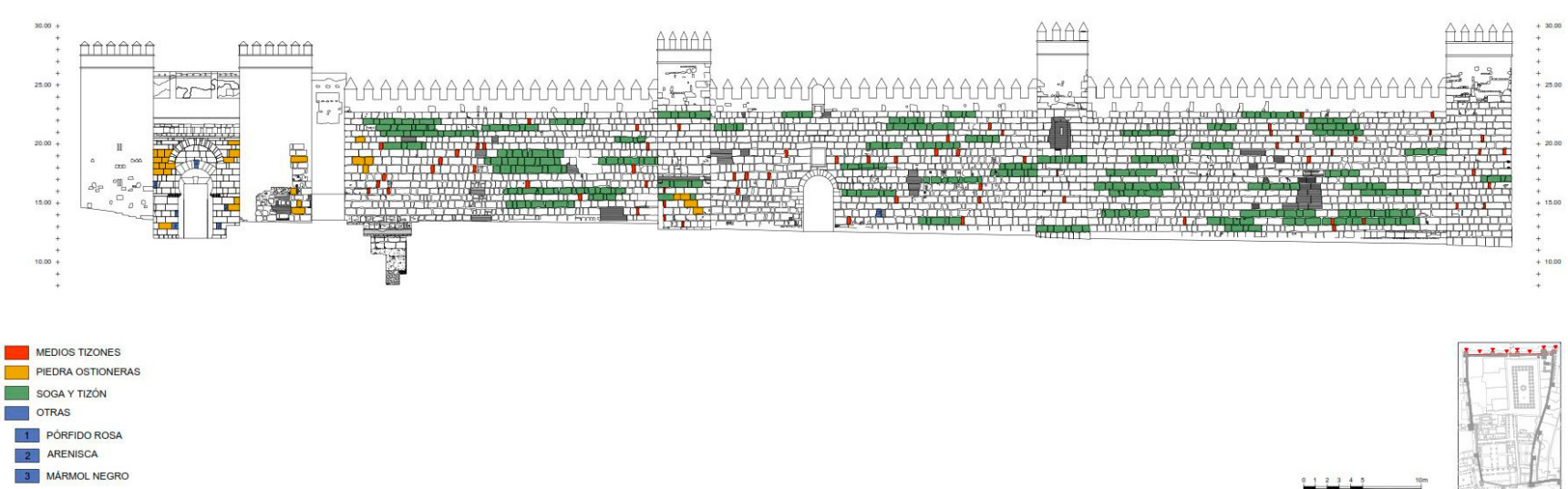

Figura 21. Lienzo Norte del primer recinto del alcázar. En rojo los medios tizones, verde las series continuas de sogas y tizones. En amarillo los sillares de piedra ostionera. En blanco piedra alcoriza y en azul otros tipos (pórfidos rosas, areniscas, yesos y mármol negro). 


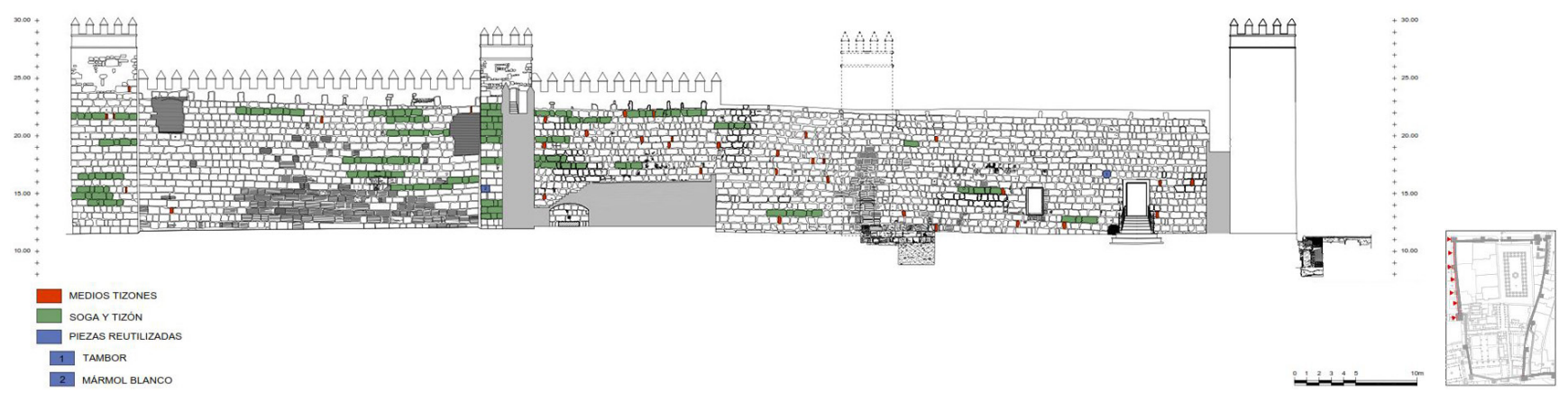

Figura 22. Lienzo Oeste del primer recinto del alcázar. En rojo los medios tizones, verde las series continuas de sogas y tizones. En amarillo los sillares de piedra ostionera. En blanco piedra alcoriza y en azul otros tipos (pórfidos rosas, areniscas, yesos y mármol negro).
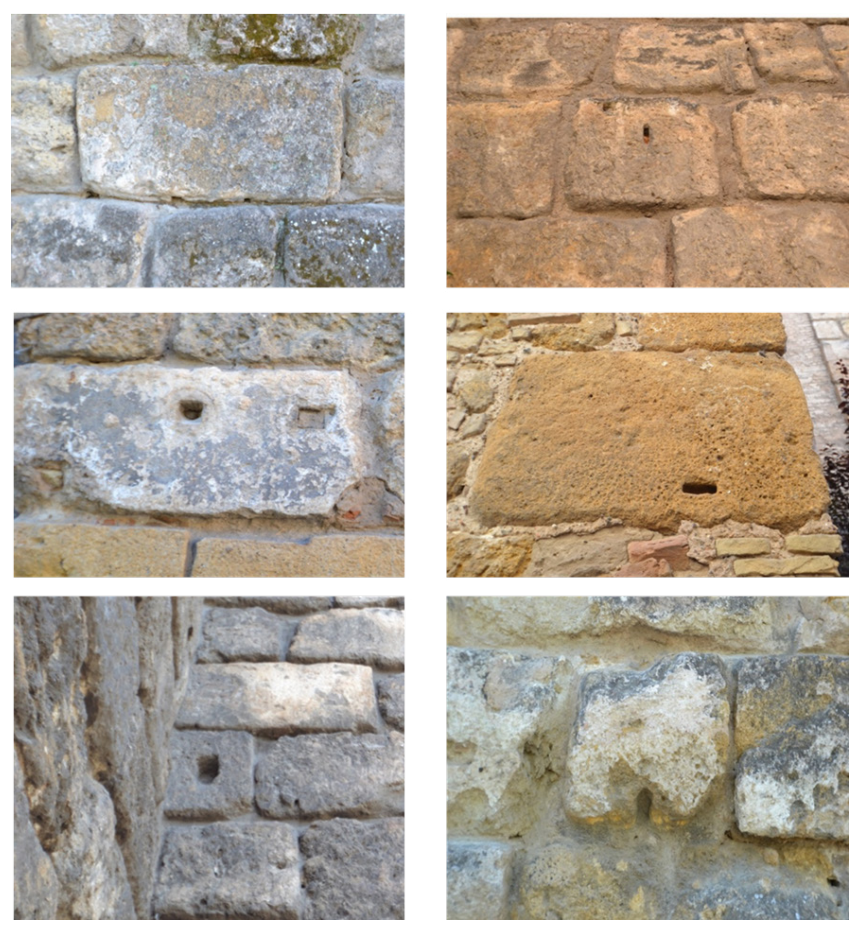

Figura 23. Huellas de acople e izado desorganizadas respecto a la posición actual del bloque, muestra de su reutilización son evidentes las improntas de los antiguos acoples mediante palancas ideados para fábricas a hueso. Se han contabilizado sólo en la cara exterior de las murallas norte y oeste, 240 huellas de izado antiguo y 120 de acoples, incompatibles con su posición actual (Fig. 23). Fueron empleadas otras piezas de origen romano además de los sillares. Casi todas ellas en el lienzo occidental, sobre todo en su mitad meridional, coincidiendo con la parte de la muralla peor ejecutada. En concreto, se han contabilizado 25 tambores de calcarenita de un codo de diámetro, algunos con estrías vivas dóricas pertenecientes a columnas similares a las localizadas en la galería del posible pórtico romano excavado en el Patio de Banderas (14) (Fig. 24). Hay cinco grandes dovelas y lo que parece ser un pedestal romano, visible en el centro del patio del León en una de las hiladas más altas.

A la altura del adarve, tanto el lienzo norte como el occidental (Tipos 1,2 y 3), sustituyen la sillería por fábricas mixtas muy irregulares sobre bloques de piedra espaciados, dispuestos verticalmente a modo de llave o anclaje para contener los movimientos de tracción presumibles en el almenado y el parapeto. Tanto en ambos elementos como en las cámaras de las torres se recurre al uso indiscriminado de fragmentos de ladrillo romano, ladrillos finos taifas y mampuesto menudo, organizados cuidadosamente, aparejados con tendencia a la horizontalidad, combinándose con sillarejos o bloques escuadrados de pequeña dimensión que sirven de diátonos regularizadores. Sorprende la mala calidad de los materiales frente a la

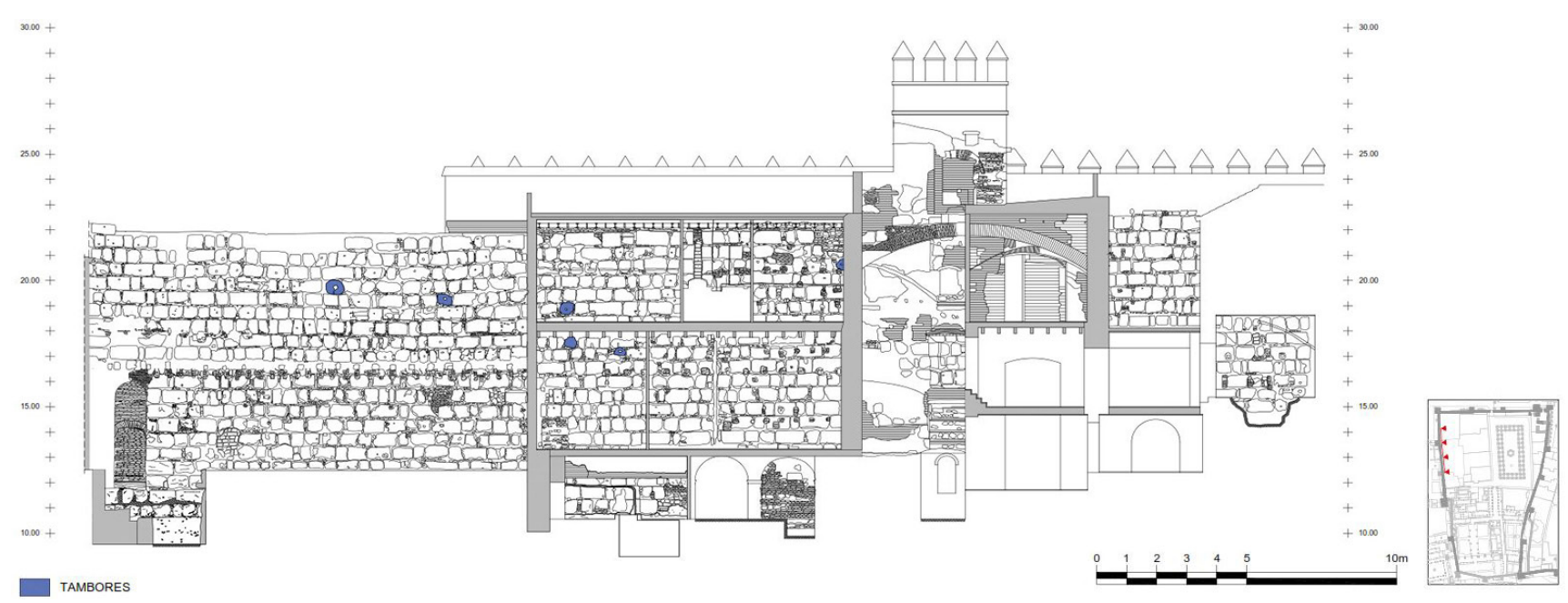

Figura 24. Lienzo occidental del primer recinto (interior). Detalle del uso de tambores pétreos de columnas romanas reutilizadas 
cuidada puesta en obra, así como el esmerado mortero de cal aglutinante. Es esta una tipología muy arraigada en la Sevilla islámica desde el siglo XI hasta los inicios del siglo XIII, tanto en muros como en cimientos (Fig. 25).

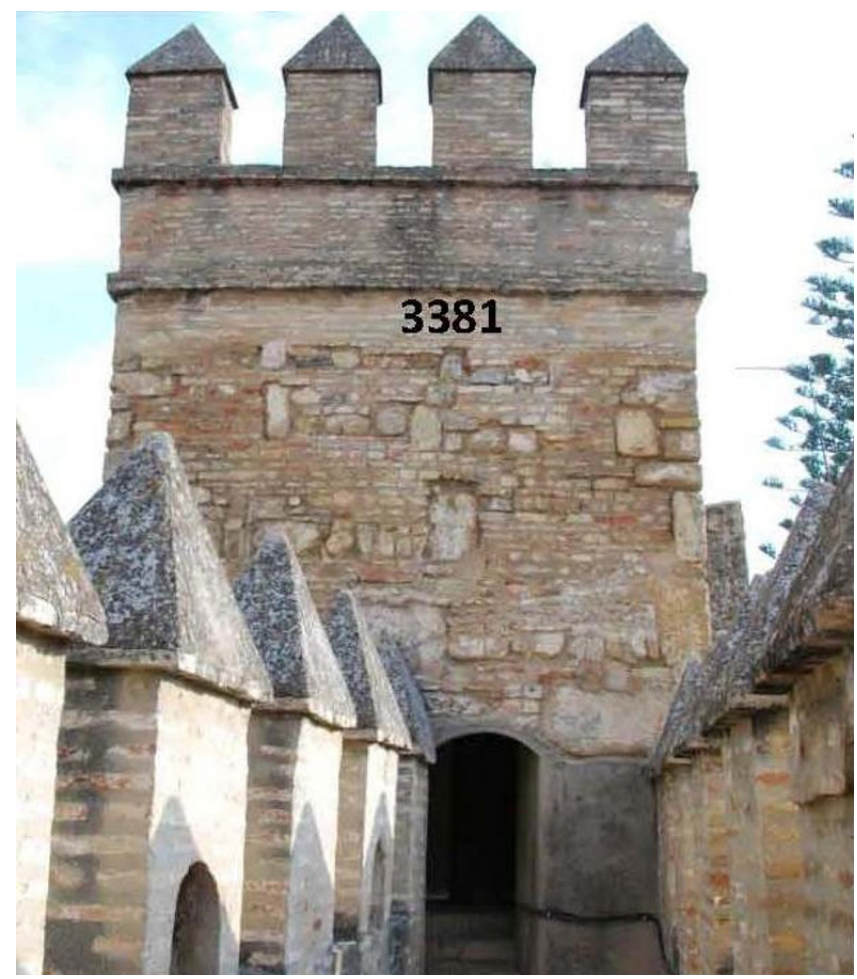

Figura 25. Aparejo mixto de la torre del León, lienzo occidental

\section{LA CRONOLOGÍA DEL PROCESO DE OBRAS}

La datación arqueológica de la fundación del alcázar y la de sus transformaciones iniciales ha sido obtenida mediante el cruce de diferentes observaciones y análisis. Por un lado, disponemos de una rigurosa y amplia estratigrafía, obtenida mediante la realización de sondeos en la base de las murallas y principales palacios, además de algunas excavaciones en área. El estudio de los materiales asociados a las cimentaciones y los distintos niveles arqueológicos han podido combinarse con un completo estudio de paramentos. De modo complementario se ha llevado a cabo una revisión de las fuentes históricas y literarias, así como un estudio de la planimetría histórica, de las fotografías de obra y de los fondos documentales de las obras realizadas durante el pasado siglo XX. Finalmente se han llevado a cabo dataciones absolutas radiocarbónicas y de termoluminiscencia en número suficiente ( $>50$ ) para ajustar en lo posible los procesos fundamentales de la secuencia (15).

En consecuencia, se ha podido concluir la siguiente secuencia de obra (Figs. 26 a 28) (Tabla 2):

1. Construcción del primer recinto.

2. Sustitución del sistema de acceso en la cara Norte y construcción de un nuevo muro oriental desplazado a fin de generar un amplio ingreso en recodo.

3. Adosamiento del segundo recinto al sur del primero.

4. Sustitución de las murallas orientales de los dos primeros recintos por una nueva muralla homogénea en la que se abre el postigo de la Judería.

5. Adosamiento al recinto segundo de la muralla del Agua.
6. Adosamiento al recinto segundo del tercer recinto al Oeste del segundo.

7. Adosamiento a los recintos dos y tres del recinto $\mathrm{n}^{\mathrm{O}} \mathrm{IV}$ al Sur de ambos.
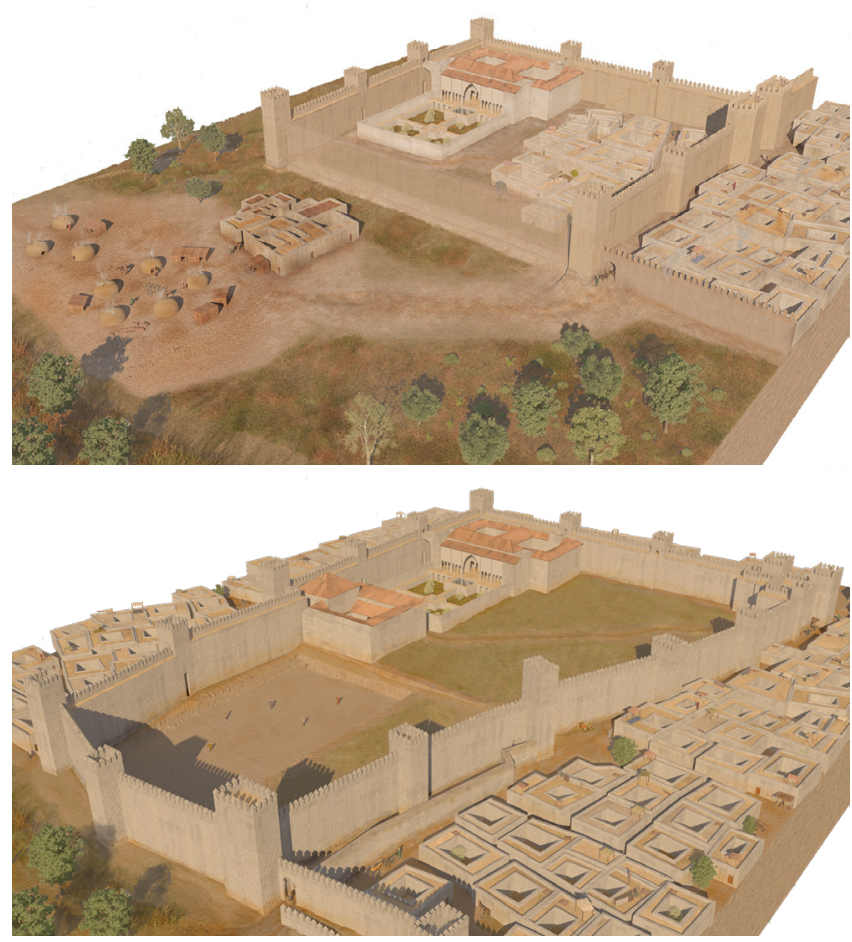

Figura 26. Proceso de Construcción del primer y segundo recintos del alcázar. (Reconstrucción virtual de Jesús García a partir de hipótesis de M.A. Tabales).

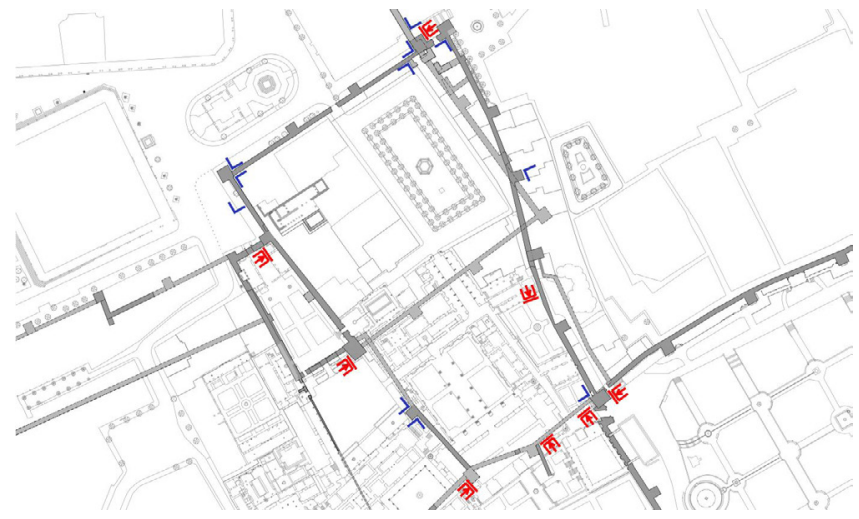

Figura 27. Sentido de contactos en los lienzos de los primeros recintos del alcázar.

Los datos disponibles nos permiten descartar definitivamente una cronología previa al siglo XI para el inicio del proceso de obras que concluiría, en lo referente a expansión urbana, a mediados del siglo XIII, durante los últimos momentos de la presencia islámica en la ciudad. A nivel de hipótesis, creemos que las obras de la muralla pétrea del primer recinto del alcázar se inician por el lado noreste durante el reinado del rey al Mutadid y avanzan hasta ser terminadas por al Mutamid, quien asentado de un modo más fiable en el trono y sujeto ya a otras necesidades de tipo más palatino que militar, iniciaría la ampliación-duplicación hacia el sur a la vez que iniciaba las obras del palacio del recinto fundacional. En ambas fases, se identifica la dualidad 

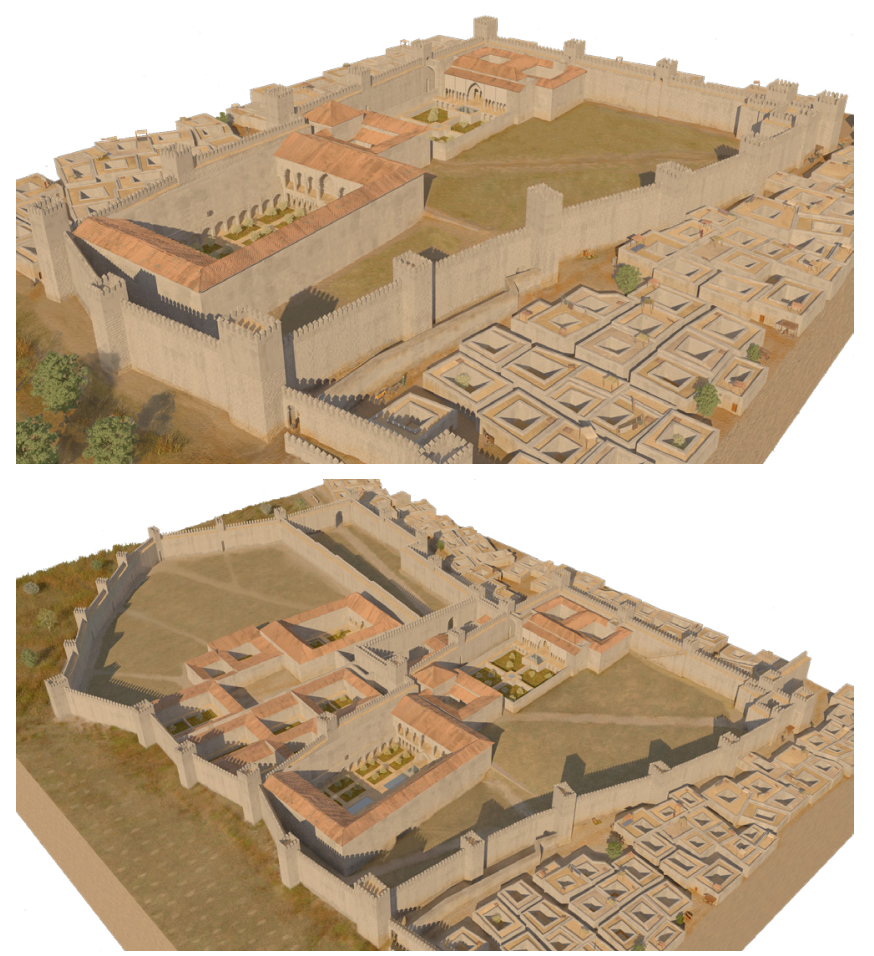

Figura 28. Transformación de los primeros recintos del alcázar (siglos XI-XII). (Reconstrucción virtual de Jesús García a partir de hipótesis de M.A. Tabales). existente en las técnicas constructivas, empleando piedra en los frentes norte y oeste, y fábricas encofradas en los restantes. De este modo, trabajarían de forma simultánea distintos especialistas, reservando siempre, como ya se ha dicho, la piedra para los alzados dotados de mayor representatividad ante la población. Incluso entre los canteros, se podría hablar de dos grados de especialización, ya que las fábricas del tipo 5 (puerta ángulo NE) denotan el uso de escuadra, mientras que en las sillerías restantes apenas se recurriría a la regla (16).

\section{CONCLUSIONES}

Aunque resulta difícil encuadrar tipológicamente el proceso analizado, al no existir estudios en profundidad de los sistemas de cimentación ni estudios técnicos de las estructuras, ni dataciones precisas en otras fortificaciones del siglo XI, podemos establecer unas pautas esenciales que justifiquen un encuadre razonable para la construcción del alcázar sevillano.

Construir con cantería es un fenómeno eminentemente cordobés, ya presente en el programa arquitectónico iniciado por 'Abd al-Rahman I siguiendo pautas orientales en la gran mezquita de la capital. En las áreas periféricas de al-Andalus (17) se pusieron en marcha programas similares, aunque sin lograr el perfeccionamiento de la talla o la estereotomía originales, al menos en el período emiral. Durante el califato se generalizó el empleo de la sillería de cantera en las construcciones promovidas por el Estado en diversos puntos de al-Andalus. Pero esta producción a gran escala se vio drásticamente truncada a principios del siglo XI, con el colapso del modelo político califal (18). Las taifas

Tabla 2. Tabla cronotipológica.

\begin{tabular}{|c|c|c|c|c|}
\hline TIPOLOGÍA & CIMENTACIÓN & ALZADO & SITUACIÓN & CRONOLOGÍA \\
\hline Tipo 1 & $\begin{array}{l}\text { - Amplia zanja con relleno preparación. } \\
\text { - Zapata escalonada con tres hiladas. Em- } \\
\text { pleo de mortero de cal. }\end{array}$ & $\begin{array}{l}\text { - Excéntrico sobre zanja cimentación. } \\
\text { - Muro tipo emplecton. } \\
\text { - Aparejo isódomo irregular de sillares reutilizados, to- } \\
\text { mados con barro. } \\
\text { - Remate fábrica mixta tomada con mortero de cal. }\end{array}$ & $\begin{array}{l}\text { - Primer recinto. } \\
\text { - Frente oeste. }\end{array}$ & $\begin{array}{l}\text { - Taifa } 1 \\
\text { (al-Mutadid). }\end{array}$ \\
\hline Tipo 2 & $\begin{array}{l}\text { - Amplia zanja con relleno de prepara- } \\
\text { ción. } \\
\text { - Zapata escalonada con dos hiladas. Em- } \\
\text { pleo de mortero de cal. }\end{array}$ & $\begin{array}{l}\text { - A eje sobre zanja cimentación. } \\
\text { - Muro tipo emplecton. } \\
\text { - Aparejo isódomo regular de sillares reutilizados a soga } \\
\text { y tizón, tomados con barro. } \\
\text { - Remate fábrica mixta tomada con mortero de cal. }\end{array}$ & $\begin{array}{l}\text { - Primer recinto. } \\
\text { - Frente norte. }\end{array}$ & $\begin{array}{l}\text { - Taifa } 1 \\
\text { (al-Mutadid). }\end{array}$ \\
\hline Tipo 3 & $\begin{array}{l}\text { - Amplia zanja con relleno preparación. } \\
\text { - Zarpa escalonada. Empleo de mortero } \\
\text { de cal. }\end{array}$ & $\begin{array}{l}\text { - A eje sobre zanja cimentación con escaso relleno pe- } \\
\text { rimetral. } \\
\text { - Muro tipo emplecton. } \\
\text { - Aparejo isódomo regular (Frente N) o irregular (Frente } \\
\text { O) de sillares reutilizados, tomados con barro. } \\
\text { - Remate fábrica mixta tomada con mortero de cal. }\end{array}$ & $\begin{array}{l}\text { - Primer recinto. } \\
\text { - Torres frentes Ny O. }\end{array}$ & $\begin{array}{l}\text { - Taifa } 1 \\
\text { (al-Mutadid). }\end{array}$ \\
\hline Tipo 4 & - Zócalo de sillares reutilizados. & $\begin{array}{l}\text { - Alzado de tapial simple. } \\
\text { - Esquinas encadenadas con fábrica mixta. }\end{array}$ & $\begin{array}{l}\text { - Primer recinto. } \\
\text { - Puerta original en frente E. }\end{array}$ & $\begin{array}{l}\text { - Taifa } 1 \\
\text { (al-Mutadid). }\end{array}$ \\
\hline Tipo 5 & - Zapata corrida de sillares. & $\begin{array}{l}\text { - Muro tipo emplecton. } \\
\text { - Aparejo isódomo de sillares con mezcla de piezas reu- } \\
\text { tilizadas y nuevas ajustadas a escuadra. } \\
\text { - Piezas colocadas a hueso. }\end{array}$ & $\begin{array}{l}\text { - Primer recinto. } \\
\text { - Nueva puerta en ángulo NE. }\end{array}$ & $\begin{array}{l}\text { - Taifa } 2 \\
\text { (al-Mutamid). }\end{array}$ \\
\hline Tipo 6 & $\begin{array}{l}\text { - Zanja cimentación sin relleno de prepa- } \\
\text { ración. } \\
\text { - Zócalo de dos hiladas de sillares y sillare- } \\
\text { jos irregulares. }\end{array}$ & $\begin{array}{l}\text { - A eje sobre zanja de cimentación. } \\
\text { - Alzado de tapial simple. }\end{array}$ & $\begin{array}{l}\text { - Primer recinto. } \\
\text { - Ampliación frente E. }\end{array}$ & $\begin{array}{l}\text { - Taifa } 2 \\
\text { (al-Mutamid). }\end{array}$ \\
\hline Tipo 7 & $\begin{array}{l}\text { - Zanja cimentación sin relleno de prepa- } \\
\text { ración. } \\
\text { - Dos cajones iniciales a modo de escarpa. }\end{array}$ & $\begin{array}{l}\text { - A eje sobre zanja de cimentación. } \\
\text { - Alzado de tapial simple. }\end{array}$ & $\begin{array}{l}\text { - Segundo recinto. } \\
\text { - Frente S. }\end{array}$ & $\begin{array}{l}\text { - Taifa } 2 \\
\text { (al-Mutamid). }\end{array}$ \\
\hline Tipo 8 & $\begin{array}{l}\text { - Zanja cimentación sin relleno de prepa- } \\
\text { ración. } \\
\text { - Sin resalte ni escarpa, más allá de la pri- } \\
\text { mera hilada, con un ligero resalte. } \\
\end{array}$ & $\begin{array}{l}\text { - Excéntrico sobre zanja cimentación. } \\
\text { - Muro tipo emplecton. } \\
\text { - Aparejo isódomo irregular de sillares reutilizados, to- } \\
\text { mados con barro. }\end{array}$ & $\begin{array}{l}\text { - Segundo recinto. } \\
\text { - Frente O (en torre de flanqueo). }\end{array}$ & $\begin{array}{l}\text { - Taifa } 2 \\
\text { (al-Mutamid). }\end{array}$ \\
\hline Tipo 9 & $\begin{array}{l}\text { - Amplia zanja con relleno preparación. } \\
\text { - Sin zapata o zócalo. }\end{array}$ & $\begin{array}{l}\text { - A eje sobre zanja de cimentación. } \\
\text { - Alzado de tapial encadenado. }\end{array}$ & $\begin{array}{l}\text { - Segundo recinto. } \\
\text { - Frente E. }\end{array}$ & - Almohade. \\
\hline
\end{tabular}


resultantes, dentro de un panorama general de desintegración política, vieron en la construcción de grandes murallas imitando a las califales, un argumento de refuerzo de sus aspiraciones de dominio, mostrando en cada caso las limitaciones en el uso de la técnica característica de cada región ante la ausencia de programas estatales y la disminución de efectivos y recursos propios de un gran estado, ahora reducidos al control de municipios y pequeños estados muy carenciales (19).

Este es el caso de Sevilla, ciudad con aspiraciones durante la dinastía abbadí, pero muy limitada por su tamaño y población, al menos al inicio de las obras; eso sí, con la enorme ventaja de disponer como material de construcción de la magnífica cantera de bloques, ya tallados, como era la muralla romana de la ciudad. En cualquier caso, los sistemas constructivos y de puesta en obra empleados eran de contrastada solvencia y recurrían a soluciones ya conocidas desde la Antigüedad. Las cimentaciones trataban de resolver los desniveles asegurando una base fir- me a los grandes alzados de sillería. Conforme crecía la obra en altura se seleccionaban los materiales y corregían los posibles fallos de replanteo, en un proceso complejo y de gran volumen. La existencia de distintas cuadrillas de especialistas se puede inferir dados los cambios sutiles en los aparejos y los encuentros de fábricas. La selección de los materiales, en otras ocasiones, respondía a criterios de propaganda, como sucede con la elección de la noble sillería para aquellas zonas más visibles para la población.

Finalizamos este estudio con una reflexión sobre la necesidad de acometer trabajos de investigación similares en otros grandes conjuntos arquitectónicos andalusíes, al ser modelos para otras edificaciones debido a su relevancia monumental e importancia histórica. Creemos que el alcázar de Sevilla no debe ser el único lugar donde las clasificaciones formales tradicionales deben completarse, verificarse o descartarse mediante la aplicación de la estratigrafía.

\section{REFERENCIAS / REFERENCES}

(1) Gurriarán Daza, P. (2004). Hacia una construcción del poder. Las prácticas edilicias en la periferia andalusí durante el califato, Cuadernos de Madinat al-Zahra, 5: 297-325.

(2) Graciani García, A. y Tabales Rodríguez, M. Á. (2008). El Tapial en el Área Sevillana. Avance Cronotipológico Estructural, Arqueología de la arquitectura, 5: 135-158.

(3) La apertura de zanjas de cimentación con mejoras del firme era habitual cuando el terreno no era compacto o existían potentes rellenos. Un caso significativo lo tenemos en la mezquita mayor cordobesa, donde para alcanzar el firme, las andanadas de columnas apoyan en potentes cimientos de sillería de más de cinco metros de altura. Marfil Ruíz, P. (1999). Avance de los resultados del estudio arqueológico de la fachada este del oratorio de 'Abd al-Raḥmān I en la Mezquita de Córdoba. Cuadernos de Madinat al-Zahra, 4: 201, Fig. 3.

(4) Tabales Rodríguez, M. Á. (2003). El Alcázar de Sevilla. Primeros estudios sobre estratigrafía y evolución constructiva. Madrid.

(5) Tabales Rodríguez, M. Á. y Vargas Lorenzo, C. (2014). La arqueología en el alcázar de Sevilla. Nuevos estudios en el recinto primitivo e investigaciones derivadas de hallazgos casuales (2012-2014). Apuntes del Alcázar de Sevilla, $\mathrm{n}^{\circ}$ 15: 9-60.

(6) Tabales Rodríguez, M. Á. (2001a). El palacio islámico localizado bajo el Patio de la Montería del Alcázar de Sevilla. Anuario Arqueológico de Andalucía 1997. Sevilla.

(7) Tabales Rodríguez, M. Á. (2001b). La transformación palatina del Alcázar de Sevilla 914-1366. Anales de Arqueología cordobesa, 12: 195-213.

(8) El empleo de fábricas mixtas de tapial, con presencia de encadenados, empieza a consolidarse en periodo almohade. Márquez Bueno, S. (2018). La tecnología constructiva andalusí: obra encofrada y revestimientos en la arquitectura militar (ss. XI-XIII). El ejemplo de las torres. Arqueología de la Arquitectura, 15: 11.

(9) Tabales Rodríguez, M.Á. (2003). El Alcázar de Sevilla. Primeros estudios sobre estratigrafía y evolución constructiva. Madrid.

(10) Tabales Rodríguez, M. Á. (2001c). Las murallas del alcázar de Sevilla. Investigaciones arqueológicas en los recintos islámicos. Apuntes del Alcázar, no 2: 6-35.

(11) Tabales Rodríguez, M. Á. (2002). La primitiva puerta del Alcázar de Sevilla. Memoria Científica. Madrid.

(12) La estructura de muro de tres hojas es habitual en las fortificaciones tempranas andalusíes, excepto en las obras oficiales califales, en las que se encuentran muros macizos de sillería en muchas ocasiones. Véase el caso de las fortificaciones erigidas en el área del estrecho de Gibraltar en el siglo X. Villada Paredes, F. y Gurriarán Daza, P. (2013). Recientes investigaciones sobre las fortificaciones del Califato Omeya en el estrecho de Gibraltar (Tarifa, Algeciras, Tánger, Ceuta), I. C. Ferreira Fernandes (coord.): Fortificações e Território na Península Ibérica e no Magreb - Séculos VI a XVI, Vol. 1: 51-62. Lisboa.

(13) León Muñoz, A. (2008). La construcción en sillería en España durante la Alta Edad Media. Una revisión de la información arqueológica. Archeologia Medievale, XXXV: 55-74.

(14) Tabales Rodríguez, M. Á. (2015). Excavaciones arqueológicas en el Patio de Banderas del Alcázar de Sevilla. Memoria de Investigación 2009-2014. Sevilla.

(15) Jiménez Hernández A. y Tabales Rodríguez, M.A. (2020): Bayesian modeling of radiocarbon and luminescence dated samples from the Reales Alcázares of Seville. En: Archaeological and Anthropological Sciences. Vol. 12. Núm. 1. https://doi.org/10.1007/s12520-019-00990-6

(16) Vendría a ser lo que se define como “varios talleres para una obra”. Caballero Zoreda, L. y Utrero Agudo, M. Á. (2012). Cómo funcionaban los talleres constructivos en la Alta Edad Media hispánica. Mundos medievales. Espacios, sociedades y poder, Tomo I: 427-439. Véase también lo referido en Utrero Agudo, M. Á. (2017). Modelos arquitectónicos y decorativos a inicios del siglo X. Algunas certezas y varias hipótesis. Arqueología y Territorio Medieval, $\mathrm{N}^{\mathrm{O}} 24$ : $185-206$. 
(17) Gurriarán Daza, P. (2014). Las técnicas constructivas en las fortificaciones andalusíes, F. Sabaté, J. Brufal (dirs.): Arqueologia Medieval: La ciutat, Agira VI: 299-328. Lleida.

(18) Calvo Capilla, S. (2011). El arte de los reinos taifas: tradición y ruptura. Anales de Historia del Arte, Volumen Extraordinario (2): 69-92.

(19) Malpica Cuello, A. (1998). Las técnicas constructivas en al-Andalus. Un debate entre la arqueología y la arquitectura. Técnicas agrícolas, industriais e constructivas na Idade Media (curso de verán, Celanova, 8-12 de xullo de 1996), 277336. Vigo. 